\title{
Consideraciones económicas, sociales y políticas del terremoto del 13 de enero
}

\author{
Centro de Información, Documentación \\ y Apoyo a la Investigación \\ $(\text { CIDAI) })^{\prime}$
}

\section{Resumen}

El propósito del artículo es realizar una aproximación global al impacto del terremoto del 13 de enero, a partir de un análisis de su incidencia en los ámbitos económico, social y político. Sin embargo, se pretende ir más allá de ese análisis, apuntando en la dirección de la responsabilidad estatal y privada en el desastre. Uno de sus principales argumentos es que el terremoto del 13 de enero ha puesto de manifiesto las grandes debilidades del modelo de gestión política y económica prevaleciente en el país. Asimismo, entre otras cosas, se concluye que el país no puede seguir -en lo político, en lo económico, en lo social y en lo medioambiental- en la ruta previa al día del terremoto.

1. En la claboración de csle arlículo participaron los siguicntes micmbros del CIDAI: Luis Armando González, Cristopher Estrada, Roody Reserve, Luis Romano y Jaime Rivas. Asimismo colaboraron en su redacción Xiomara Peraza, Roxana Marıll c Ivón Rivera (del Departamento de Letras y Comunicaciones de la UCA), Lidia Salamanca (del Departamento de Arquitectura de la UCA) y el periodisla Marcos Rivera. 
El 13 de enero fue un día dramático para los salvadoreños. Hacia las 11:35 a.m. un fuerte sismo (7.6 en la Escala de Ritcher) sacudió fuertemente el territorio nacional. Los daños materiales y humanos provocados por el fenómeno telúrico fueron inmediatos: personas muertas y lesionadas, destrucción parcial o total de viviendas, derrumbes en cerros y colinas, pánico colectivo, dolor e incertidumbre. En cosa de segundos, la estabilidad conquistada se vino abajo para quienes fueron directamente golpeados por el terremoto. La poca o mucha seguridad material y familiar que pudo haberse tenido hasta el momento, de pronto, se convirtió en ruinas. El sismo no sólo destruyó viviendas, colinas y cerros: desmembró hogares, se llevó consigo a jefes de familia, hijos, hijas, tíos, tías y abuelos. Sin duda, el impacto más grave del sismo fueron las muertes que dejó tras de sí. Muertes individuales, sí, pero también muerte colectiva e impredecible. Los bienes materiales - con todo y lo difícil que pudo haber sido su adquisición- no constituyen una pérdida irreparable: sí lo es la vida de quienes quedaron soterrados. Nada ni nadie, al menos en este mundo, podrá devolverlas.

Tras la pérdida de bienes y vidas humanas, sucedida como resultado inmediato del terremoto, siguieron las dificultades para hacer frente a las necesidades de quienes, pese a haber salvado su vida, se quedaron sin nada y dependían para sobrevivir de la ayuda que las instancias públicas o privadas pudieran ofrecerles. Ciertamente, la respuesta inmediata de diversos sectores de la sociedad no se hizo esperar, ante todo la de los medios de comunicación, algunos de los cuales, además de asumir los riegos de la labor informativa, en esas circunstancias, sirvieron de canales para el acopio y la distribución de ayuda a las víctimas. La labor humanitaria de los medios fue apoyada por cientos de personas de buena voluntad, que acudieron al llamado de radios y canales de televisión con medicinas, ropa, comida y agua.

Con todo, a nivel institucional, la respuesta de las autoridades no sólo fue tardia, sino que se caracterizó por la improvisación y, cuando se concretó, por el excesivo celo burocrático. Tras estas fallas, se hizo patente un problema de fondo: la inexistencia de un plan gubernamental para hacer frente a situaciones de desastre como la suscitada por el terremoto del 13 de enero. En ausencia de un plan de esta índole, el Comité de Emergencia Nacional (COEN) no supo qué hacer, ni en las tareas de rescate ni en las tareas de atención a las víctimas; ante ello, se hizo necesaria una medida que -de cumplir el COEN con su mandato- hubiera sido innecesaria: la creación, a iniciativa del presidente Francisco Flores, de la Comisión Nacional de Solidaridad (CONASOL), integrada por prominentes figuras de la empresa privada, ligadas estrechamente al Partido ARENA.

Tanto al COEN como a CONASOL $-y$, a través de ambas instiluciones, a la Presidencia de la República- les llovió, desde muy temprano, una andanada de críticas -que todavía continúan- no sólo por su inefectividad, sino por su política de centralización de la ayuda, la cual marginó a quienes estaban más cerca de las necesidades de los afectados: alcaldías, iglesias y organizaciones no gubernamentales. Esas críticas arreciaron a medida que los días iban transcurriendo y la ayuda no llegaba a su destino, o si lo hacía, era en cantidades insuficientes para las ingentes demandas surgidas en los municipios y comunidades más golpeadas.

Inicialmente, los voceros gubernamentales desestimaron las críticas por considerar que eran expresión de una campaña montada por el FMLN y sus "aliados"; posteriormente, el presidente Flores anunció un cambio de marcha en la logística de entrega de la ayuda, que esta vez sí se apoyaría en los consejos municipales. Pese a ello, el malestar de los ciudadanos no disminuyó, ya que el ofrecimiento gubernamental, además de tardío, introdujo nuevas trabas: por ejemplo, las alcaldías iban a canalizar la ayuda, pero tendrían que valerse de sus propios medios para transportarla del Aeropuerto de Comalapa hacia las comunidades. Adicionalmente, un ofrecimiento de ayuda económica del gobierno (de 1500 colones por familia afectada) para la limpieza de escombros generó malestar y confusión en los municipios: por un lado, los pobladores entendieron que ese dinero se les iba a entregar integra e inmediatamente en las alcaldías; por otro, los alcaldes o no habían recibido tales fondos o lo recibido era insuficiente para atender las necesidades de los afectados. Eso no pudo menos que contribuir aún más al desaliento social, provocado de nuevo por la incompetencia administrativa (y política) del gobierno central.

La tragedia del 13 de enero ha sido aleccionadora en muchos sentidos. Por el lado positivo, ha puesto de manifiesto algo que los más pesimistas ya daban por perdido: la disposición de miles de salvadoreños para ayudar a quienes fueron vícli- 
mas del impacto del sismo. Existe un potencial de solidaridad colectiva en los salvadoreños que salió a relucir ese 13 de enero y en los días que siguieron al desastre. Desaprovechar ese potencial, no encauzarlo hacia la construcción de una sociedad más equitativa y democrática, sería un error imperdonable. La forma más fácil de dilapidar esa energía social es no tomarla en cuenta, considerarla inexistente, o peor aún, intentar manipularla a partir de propósitos sectarios — partidaristas o como se les quiera llamar-, sean del color que sean.

Lo sucedido el 13 de enero también ha puesto de manifiesto las grandes debilidades del modelo de gestión política y económica prevaleciente en el país. En primer lugar, ha salido a relucir la ausencia de un plan de emergencia desde el cual, antes que nada, se puedan prevenir desastres; y, de generarse una catástrofe, se puedan emprender con eficacia y prontitud las tareas de rescate y de atención a las víctimas. En segundo lugar, se han hecho patentes las graves fallas del esquema de expansión urbana dominante en el país, en el cual entretejen la irresponsabilidad estatal y privada, las ambiciones empresariales, la corrupción, la ignorancia y una visión de los recursos naturales como algo que debe ser depredado sin consideración alguna. En tercer lugar, se ha puesto en evidencia lo peligroso que es para la sociedad vivir de espaldas a una realidad proclive a la imupción destructiva de fenómenos naturales como terremotos e inundaciones. Se ha insistido hasta la saciedad en la creación de una cultura de paz, lo cual está bien. Pero es necesario avanzar hacia una formulación más englobante como lo sería una "cultura del riesgo". La sociedad salvadoreña es una sociedad atravesada por riesgos sociales y naturales ante los cuales no se deben cerrar los ojos, so pena de ser sorprendidos por ellos de la manera más despiadada.

La destrucción provocada por el terremoto liene unos costos humanos y materiales que deben ser vistos en todo su alcance, al igual que lo deben ser los costos de la reconstrucción. Son la expresión de lo que le cuesta al país y a sus habitantes el modelo de gestión política y económica vigente, la irresponsabilidad estatal y privada, y la actitud depredadora de los recursos naturales, que no es exclusiva de los constructores, sino que forma par-

te de la identidad cultural de una buena parte de los salvadoreños. El desastre del 13 de enero indica con claridad que el país no puede seguir —en lo político, en lo económico, en lo social y en lo medioambiental - por la ruta previa al dia del terremoto.

Poner a El Salvador en la misma dirección sería crear una antesala para que tragedias como la de La Colina se vuelvan a repetir. Y eso no puede ser querido por nadie que respete sinceramente la vida humana. Las páginas que siguen —en las cuales se hace una aproximación global al impacto del terremoto del 13 de enero-, más allá del análisis de su impaclo económico, social o político, quieren apuntar en la dirección de la responsabilidad estatal y privada en el desastre. Los grandes empresarios de la construcción y los funcionarios encargados de regular y verificar sus actividades deben saber de una vez por todas que la irresponsabilidad no puede ni debe ser tolerada, sobre todo si están de por medio vidas humanas.

\section{Algunas consideraciones conceptuales}

Al analizar el tema de los desastres debe tomarse como punto de partida el hecho de que estos no son meramente fenómenos naturales (como un terremoto o un huracán), sino más bien el efecto de aquéllos sobre un conglomerado social que no tiene capacidad para resistir ni para recuperarse tan fácilmente del impacto. Incluso algunos fenómenos aparentemente naturales pueden en realidad ser precipitados por acciones de los seres humanos sobre los ecosistemas (este es el caso de algunos tipos de inundaciones, derrumbes y deslizamientos). La complejidad de la problemática obliga a 
tener en cuenta modelos conceptuales para analizar el tema de los desastres, pues de ello depende qué tan efectivas sean las políticas públicas para reducir el riesgo y acercarse al desarrollo sostenible. En este apartado se retoman brevemente los elementos fundamentales que integran el riesgo de desastres, para evidenciar la vinculación existente entre los ámbitos físicos, ambientales, económicos y sociales y la ocurrencia de los desastres. Esta vinculación se pone de manifiesto en la siguiente fórmula:

\section{Riesgo $=$ amenaza $x$ vulnerabilidad}

En donde el "riesgo" de desastres depende en forma directamente proporcional de las "amenazas" y "vulnerabilidades" presentes en un lugar y momento determinados. Estas amenazas y vulnerabilidades se caracterizan, en términos generales, en los siguientes apartados ${ }^{2}$.

\subsection{Las amenazas}

Dentro de los enfoques teóricos para analizar los desastres, las amenazas se clasifican en tres grandes tipos: las amenazas naturales, las amenazas socionaturales y las amenazas antrópicas. Las amenazas naturales surgen exclusivamente de las dinámicas del planeta y no pueden ser afectadas por acciones humanas; consecuentemente, tampoco son posibles de evitar. Éstas, a su vez, pueden clasificarse en hidrometeorológicas y geológicas; las primeras comprenden eventos tales como huracanes, temporales, sequias y granizadas, mientras que las segundas se refieren a fenómenos como terremotos, erupciones volcánicas, derrumbes, deslizamientos y hundimientos. Las amenazas socionaturales surgen de las reacciones que tiene la naturaleza frente a las acciones humanas y comprenden fenómenos tales como erosión, deforestación, desecación de pantanos y cierto tipo de derrumbes y deslizamientos, que no son inducidos solamente por causas naturales, sino más bien por el efecto de actividades humanas sobre la estabilidad del terreno. Finalmente, las amenazas provocadas por el ser humano (o antrópicas), tal como su nombre lo indica, son resultado de las acciones de la humanidad sobre los recursos naturales (agua, aire y tierra), los ecosistemas o sobre la población y comprende fenómenos tales como la contaminación, el almacenamiento de substancias peligrosas (corrosivas o explosivas), sin las debidas medidas de precaución, y la construcción de obras de infraestructura sin previsiones ambientales.

\subsection{Las vulnerabilidades}

La vulnerabilidad es la incapacidad de resistir los efectos de un evento amenazante (como los descritos en el apartado anterior) o la incapacidad de recuperarse después de que ocurre un desastre. Las vulnerabilidades surgen a partir de la forma en que la sociedad está estructurada en lo relativo a cuatro diferentes grupos de factores: físicos, ambientales o ecológicos, económicos y sociales. De los cuatro grupos, son los factores sociales los que presentan más divisiones y, al mismo tiempo, donde se presentan las posibilidades más concretas para cambiar una situación de riesgo por una de desarrollo. A continuación, se revisan brevemente cada uno de estos cuatro grupos de factores de vulnerabilidad.

(a) Factores físicos de la vulnerabilidad: ubicación de los asentamientos humanos. Buena parte de la vulnerabilidad surge por la ubicación de asentamientos humanos, en zonas de alta peligrosidad sísmica $y / 0$ volcánica $y / 0$ en zonas propensas a inundaciones, derrumbes y deslizamientos. La mayoría de veces, ello obedece a condicionamientos sociales. Por ejemplo, para los pobladores de zonas marginales, habitar a la orilla de quebradas y taludes, significa una reducción de la vulnerabilidad frente a la vida, pero los coloca en situación más vulnerable ante inundaciones y derrumbes.

Condiciones de las viviendas. Hay condiciones técnicas y materiales que provocan mayor vulnerabilidad física, como, por ejemplo, las construcciones de adobe sin técnicas de reforzamiento o las viviendas de ladrillo, construidas sin las debidas fundaciones y puntos de apoyo.

(b) Factores ecológicos. Estos surgen cuando una comunidad utiliza de forma no sostenible los elementos de su entomo, con lo cual debilita la capacidad de los ecosistemas para absorber, sin traumatismos, las amenazas naturales. Esto es especialmente cierto para el caso de las cuencas hidrográficas, las cuales pueden llegar a perder su capa-

2. La conceptualización corresponde a los estudios de La Red de Estudios Sociales en Prevención de Desasıses en América Latina. Véase Wilchez Chaux, 1998. 
cidad de regular las inundaciones, debido a procesos de deforestación, erosión, sedimentación de cauces de cuerpos de agua y reducción de su capacidad de conducción.

(c) Factores económicos. Estos tienen que ver, obviamente, con una insuficiente dotación de recursos económicos o de ingresos en una comunidad; pero también con la mala utilización de los recursos disponibles, en el sentido de que se usan para financiar actividades que puedan generar mayor riesgo. Los bajos salarios en los empleos formales y los pocos ingresos que se generan con las actividades informales o de cuenta propia, provocan que muchas familias no tengan acceso a una adecuada alimentación, educación, salud y vivienda, con lo cual se generan más factores de vulnerabilidad social y física. Aun y cuando se perciban ingresos adecuados, es posible que estos se utilicen de forma inadecuada, en tanto que, al final, incrementan el riesgo, en lugar de reducirlo. Considérense, para el caso, los programas de financiamiento de viviendas urbanas en zonas de riesgo por derrumbes.

\begin{tabular}{c}
\hline La vulnerabilidad es la incapacidad \\
de resistir los efectos de un evento \\
amenazante o la incapacidad \\
de recuperarse después de que ocurre \\
un desastre. Las vulnerabilidades \\
surgen a partir de la forma en que la \\
sociedad está estructurada en lo relativo \\
a cuatro diferentes grupos de factores: \\
físicos, ambientales o ecológicos, \\
económicos y sociales.
\end{tabular}

(d) Factores sociales de la vulnerabilidad. Se refieren a la forma en que están construidas las relaciones sociales, las visiones sobre los desastres, la organización y los comportamientos de personas, instituciones y localidades. Dependiendo de sus características, pueden generarse condiciones de mayor o menor vulnerabilidad, éstas pueden clasificarse en cinco diferentes lipos: políticos, educativos, ideológicos y culturales, institucionales y organizativos.

Ante todo, los factores políticos surgen de la limilada capacidad de las comunidades para tomar decisiones o para influir en la toma de decisiones; ello está íntimamente relacionado con la participación de la comunidad o localidad en las instancias políticas y, sobre todo, en las decisiones polílicas que le afectan. Este tipo de vulnerabilidad puede relacionarse lambién con la gestión y negociación frente a agentes externos que pueden afectar sus condiciones de riesgo (para bien o para mal). Dos importantes fuentes de vulnerabilidad política son la ausencia de canales efectivos para transmitir demandas a los ámbitos políticos y la ausencia de planes de desarrollo de parte de las comunidades en riesgo.

En segundo lugar, los factores educativos comprenden la relación que existe entre los contenidos y métodos con los cuales se educa a las nuevas generaciones y su entomo natural, físico, económico y social. Muchas veces, los programas educativos responden a necesidades de otras épocas o a intereses de grupos minoritarios. Es necesario que los contenidos y métodos educativos respondan a la realidad y a las necesidades de los sectores más necesitados. Ni a nivel de la educación primaria y básica ni de la formación universitaria se cuenta con programas de esludio que incorporen la temática del riesgo, las amenazas, las vulnerabilidades $y$ las formas en que pue de actuarse para prevenir y mitigar, de tal manera que permitan ir reduciendo la frecuencia e intensidad de los desastres. De la misma manera, tampoco se contemplan contenidos en la temática de la preparación para la atención de emergencias, provocadas por el impacto de terremotos o inundaciones.

En tercer lugar, los factores ideológicos y culturales lienen que ver con la forma cómo se conciben los desastres, al igual que con el modo cómo un conglomerado humano se enfrentará a los mismos. Mientras no se cambien las interpretaciones equivocadas de los desastres - la más común es la que plantea que los mismos son solamente un fenómeno natural-, difícilmente se arribará a propuestas de prevención y mitigación, pues los fenómenos naturales son imprevisibles e imposibles de evitar. Así, la vulnerabilidad ideológico-cultural surge como resultado de una noción parcializada de los conceptos de riesgo y desastre, en la cual estos últimos son reducidos al conceplo de amenaza natural. De aquí es que surgen los enfoques tradicionales, en los cuales los desastres aparecen como "inevitables" e "imprevisibles", por lo cual lo único que queda por hacer es estar preparados para cuando éstos sucedan. 
En quinto lugar, los factores institucionales hacen referencia a las prácticas de las instituciones, tanto del gobiemo central como de los gobiernos municipales, que impiden una adecuada adaptación a la realidad de los desastres $\mathrm{e}$, inclusive, una rápida respuesta de las instancias respectivas. Un primer problema surge en la medida de que el Estado hace frente al problema de los desastres desde una perspectiva de atención de la emergencia, la cual, aunque urgente, no es la única ni la más importante alternativa, pues también existe la posibilidad de desarrollar acciones de prevención y miligación. Un segundo problema surge de la misma estructura de las instituciones, caracterizada por la burocracia, la politización, la corrupción, la duplicidad de funciones y los excesivos trámiles como requisitos previos para tomar decisiones.

Por último, los factores organizativos están estrechamente relacionados con la capacidad de las comunidades para organizarse, establecer lazos de solidaridad y cooperación, y promover acciones conjuntas, que promuevan el desarrollo y la satisfacción de las necesidades básicas de sus miembros. En la medida que exista organización al interior de las comunidades, en esa medida también se contará con elementos para hacer frente a los desastres, no solamente desde la perspectiva de la alención de la emergencia, sino también de la reducción o eliminación de los diferentes factores de vulnerabilidad presentes en una localidad específica, lo cual va indisolublemente ligado con el mejoramiento de las condiciones de vida de las poblaciones respectivas.

\section{Ordenamiento territorial y construcción de viviendas}

Nuevamente, el alto grado de vulnerabilidad de nuestro territorio $y$, particularmente, de la pobla- ción pobre ubicada en zonas de riesgo, quedó claramente al descubierto después del terremoto del pasado 13 de enero". Casos como el deslizamiento en la cordillera del Bálsamo, que ocasionó el desastre de La Colina, en Santa Tecla, y Comasagua, en La Libertad son ejemplos claros de la ausencia de mecanismos de planificación territorial y del daño que, poco a poco, el mal llamado "desarrollo urbano" está ocasionando a nuestros recursos naturales. La necesidad de planificar el territorio de manera sostenible, en equilibrio con el medio ambiente, identificando zonas de riesgo ambiental, definiendo las potencialidades de uso del territorio y estableciendo mecanismos de manejo de la tierra urbana, es un reclamo no reciente, que surge con mayor fuerza cada vez que se produce un fenómeno que deja en evidencia la debilidad de la planificación, en el plano nacional. El terremoto también mostró que la calidad de la vivienda es otro factor determinante del riesgo en El Salvador, sobre todo, de la vivienda informal y marginal a la que tiene acceso la mayor parte de la población pobre del país.

(a) La calidad de la vivienda. Un rasgo común del impacto que han ocasionado los últimos terremolos es el daño a las viviendas de adobe y bahareque. Según datos oficiales, el terremoto del 13 de enero dañó un total de 130 005 viviendas y destruyó tolalmente otras 92080 . El impacto mayor ocurrió en el departamento de Usulután, con un lotal de 27045 viviendas destruidas y 26418 dañadas. Siguen en importancia, La Paz, con 16088 viviendas destruidas y 21848 dañadas, y La Libertad con 15701 viviendas destruidas y 14558 dañadas. Del tolal de las estructuras colapsadas, la mayor parte eran construcciones de adobe y bahareque 5 . De más está decir que ambos sistemas constructivos son característicos de las zonas rura-

3. El terremoto del $\mathbf{1 3}$ de febrero, un mes después del que se hace referencia en el artículo, confirma que la población pobre es la más afectada por fenómenos como terremotos o inundaciones, que dañan no solamente la vivienda, sino toda su infraestructura productiva y social.

4. Datos publicados por el Comité de Emergencia Nacional.

5. El último terremoto del 13 de febrero ocasionó daños severos en los departamentos de Cuscatlán, La Paz y San Vicente, en la zona paracentral del país. Las viviendas que sufrieron daños en enero, colapsaron con este segundo sismo. Por lo menos el 90 por ciento de las viviendas colapsadas estaban construidas con adobe o bahareque. 
les y suburbanas del país, debido en parte a que emplean materiales locales accesibles a la población y que permiten, a aquellos que no tienen otra posibilidad, contar con una estructura que satisfaga sus necesidades primarias de albergue. Aunque el adobe y el bahareque permiten la construcción de una solución habitacional accesible para la población de escasos recursos, el problema es que son materiales altamente vulnerables cuando son utilizados de manera deficiente y, en la mayoría de los casos, en zonas de alto riesgo.

Según reconocen los especialistas, las construcciones de adobe ofrecen muy poca resistencia a los movimientos sísmicos, sobre todo por su elevado peso y la rigidez de la edificación; mientras que el bahareque funciona de mejor forma, por su combinación de madera y tierra. Sin embargo, el uso de techo pesado, como las tejas, aumenta su vulnerabilidad. Otro factor a considerar es que ambos sistemas se deterioran rápidamente, si no cuentan con medidas que les protejan de la intemperie, los insectos y los roedores. De ahí que el mantenimiento constante de los repellos es imprescindible como medida de protección.

Se han hecho estudios e investigaciones técnicas que proponen formas para mejorar los sistemas constructivos tradicionales. Por ejemplo, se habla de adobe estabilizado y sistemas sismo resistentes, así como de modificar la forma y las características de la teja para disminuir el peso de los techos, entre otras propuestas. Esto supone un acercamiento técnico a la población, que no tiene más opción que seguir utilizando materiales locales para la construcción de sus viviendas. Con todo, lo que debe tenerse claro es que tratar de disminuir la vulnerabilidad de la población que vive en condiciones informales y marginales, no solamente requiere de estudios $e$ investigaciones técnicas, sino también medidas estructurales que acerquen a la población de escasos recursos a unidades habitacionales que realmente puedan llamarse "viviendas".

(b) Uso del territorio. El acelerado crecimiento poblacional en las zonas urbanas, la falta de mecanismos de planificación sostenible del territorio y el deficiente marco legal, generan procesos como la urbanización en zonas inapropiadas, no sólo de asentamientos informales, sino también de proyectos de vivienda para sectores de altos ingresos. El impacto que el terremoto ocasionó en la zona sur de Santa Tecla, dejando prácticamente inhabitable todas las urbanizaciones ubicadas al pie de la cordillera del Bálsamo, es una muestra del efecto negativo que está generando la creciente urbanización y la demanda desproporcionada de tierra urbana. Este ritmo acelerado de ocupación del suelo ha llevado a la transformación de zonas con vocación agrícola en zonas de uso habitacional. En el área metropolitana de San Salvador, durante la década de los años setenta, el crecimiento se orientaba hacia las zonas norte $y$ noreste, destinada anteriormente a cultivos varios y a la caña de azúcar; en los ochenta se pasó a utilizar la zona sur y sudeste, dedicada principalmente al cultivo de café, lo cual generó cada vez mayor deforestación en el terrilorio.

Al mismo tiempo, la población pobre que migraba hacia los centros urbanos y que no tenía acceso a los sistemas formales de vivienda, se asentó en zonas de alto riesgo, principalmente en las orillas de las quebradas y en los derechos de vía de las calles, carreteras y líneas férreas. Después del terremolo, los ritmos y las características del crecimiento urbano se verán seriamente modificados. Es probable que la población que se estaba asentando en la zona sur del área metropolitana tienda a presionar nuevamente a la zona norte y crezca de manera desproporcionada la demanda de tierra urbana en los municipios de dicha zona. Si no se planifica este nuevo movimiento poblacional pondrá en crisis a estos centros poblados. Esta crisis de los centros urbanos, producto del desequilibrio entre urbanización y recursos naturales, aumenta las posibilidades de que ocurran desastres cuando se dan fenómenos como los terremolos o las inundaciones.

(c) La planificación en el proceso de reconstrucción. Según estudios realizados, la zona de 
mayor peligrosidad sísmica en El Salvador es la cadena volcánica, la parte noreste de la cordillera costera y la parte sur-oeste del valle interior; mientras que la zona norte del país es considerada como la zona con menor amenaza sísmica. Contradictoriamente, en la zona de mayor peligrosidad se ubican los principales centros urbanos, concentrando por lo menos a tres cuartas partes de la población nacional y a la mayor parte de infraestructura social y productiva del país; mientras que en la zona norte hay menos concentración poblacional y muy poca inversión en infraestructura. La fuerte presión poblacional en estos centros urbanos, sobre todo después del impacto que el terremoto ocasionó ${ }^{7}$ el constante deterioro ambiental y la crisis de la tierra urbana generan desequilibrios que no deben pasarse por alto al impulsar un proceso de reconstrucción.

Desastres como el deslizamiento en Santa Marta, a raiz del terremoto de octubre de 1986 , donde murieron 200 personas y quedaron solerradas cien viviendas y el impacto del sismo del pasado 13 de enero, que provocó la muerte de más de 400 personas en La Colina, muestran que no es viable continuar construyendo nuestras ciudades sin diseñar instrumentos de planificación que permitan ordenar el uso de suelo y optimizar los pocos recursos con los que contamos. Iniciar un proceso de reconstrucción sin la identificación de las zonas de riesgo ambiental, principalmente en los grandes centros poblados del país, y sın la creación de instrumentos de ordenamiento territorial, provocaría que fenómenos como el de Santa Marta, en 1986, y La Colina, en el 2001, sigan ocurriendo cada vez que se produce un terremoto $o$ una inundación.

Está fuera de duda la necesidad de contar en El Salvador con un esquema de ordenamiento territo- rial, que incorpore el factor de prevención de desastres. Impulsar un proceso de este tipo implica la identificación y evaluación de las zonas de mayor riesgo, los usos potenciales más adecuados de los suelos, la búsqueda de incentivos que favorezcan la incorporación de la población en la optimización del territorio y la posible reubicación de asentamientos humanos, que se encuentren en zonas de alta peligrosidad, especialmente, cuando se trata de asentamientos informales. Impulsar este proceso no es solamente responsabilidad del gobierno central, sino también de los gobiernos locales como promotores del desarrollo, y, en este caso, de la reconstrucción. Importante es la incorporación de los diferentes actores en este proceso; su participación es básica desde lo local, regional y nacional, lo cual supone un cambio radical del proceso tradicional de planificación territorial.

\section{Impacto económico}

Desde las primeras horas del terremoto del 13 de enero del 2001, se conocieron algunas evaluaciones sobre el impacto económico, basadas fundamentalmente en las pérdidas originadas directamente por el desastre. Así, el gobierno fijaba en un millón de dólares sus estimados iniciadeterminante del riesgo en El Salvador, les de pérdidas, lo cual sobre todo, de la vivienda informal y equivale aproximadamarginal a la que tiene acceso la mayor mente a un 8 por ciento parte de la población pobre del país. del producto interno bruto del año 2001. Sin embargo, el impacto económico del desastre se reflejará también en el futuro, debido a la incidencia que las pérdidas directas tendrán sobre la producción y el empleo, pues habrá un inevitable debilitamiento de las capacidades del aparato productivo. Se necesita, entonces, un enfoque más amplio que incorpore estos efectos, ya que ello también permitirá visualizar los grandes retos que deben ser enfrentados por la política económica.

6. La zona de mayor peligrosidad se define no solamente por la recurrencia de terremolos, sino también por la presencia de fallas geológicas y por las caractcrísticas de suclo, que detcrminan su comportamicnto durantc los sismos o las inundaciones.

7. Tanto el terremoto de enero como el de febrero causaron un impacto importante en cl árca rural del pais, por lo que la presión en los centros urbanos se cspera que sca lodavía mayor. 
Desde la década de 1970, la Comisión Económica para América Latina y el Caribe (CEPAL) ha venido evaluando el impacto de desastres de gran envergadura en América Latina ${ }^{z}$, aunque no fue hasta principios de la década de 1990 que se sistematizó y redactó un enfoque metodológico para la evaluación económica de aquéllos". En lo fundamental, esta metodología plantea que la evaluación económica de los desastres debe considerar tres elementos: efectos directos, efectos indirectos y efectos secundarios ${ }^{16}$.

Los efectos directos consisten en "perjuicios en los acervos que acaecieron prácticamente durante el lapso mismo en que ocurrió el siniestro"'". Esto implica considerar pérdidas de infraestruclura física, maquinaria y equipos, mobiliario, medios de transporte, daños en tierras agrícolas y sistemas de riego. Por otra parte, los efectos indirectos "se refieren básicamente a los flujos de bienes que se dejan de producir o de servicios que se dejan de prestar durante un tiempo que se inicia apenas acaecido el desastre y puede prolongarse durante el proceso de rehabilitación y reconstrucción"'? Algunos ejemplos de este tipo de daños, según la CEPAL, son los siguientes: "pérdidas de cosechas futuras debido al anegamiento de tierras agrícolas; las pérdidas de producción industrial por daños en las plantas o por falta de materia prima; los mayores costos de transporte originados por la necesidad de utilizar vías o medios alternos de comunicación que son más largos o costosos; los menores ingresos en las empresas de servicio por la interrupción de estos; los impuestos no percibidos por el fisco, originados por la menor actividad económica, etc."13.

Finalmente, los efectos secundarios "denotan la incidencia del desastre sobre el comportamiento de las principales variables macroeconómicas"14

como, por ejemplo, la producción, el empleo, la balanza comercial (tanto porque se reducen las exportaciones como porque se incrementan las imporlaciones), las finanzas públicas, los incrementos en los precios y la oferta monetaria, los retrasos en el proceso de dolarización y el incremento de las remesas familiares. Es importante tener en cuenta que, de acuerdo a la misma CEPAL, los efectos secundarios "reflejan las repercusiones de los daños directos e indireclos, por lo que no deben agregarse a aquellos"15. Lo importante de los costos secundarios es que nos dicen qué tanto pierde (o puede perder) una sociedad, en términos de estabilidad macroeconómica y, además, qué tanto deja de crecer su producción por efecto de un desastre.

\subsection{Los costos económicos: evaluación prelimi- nar}

El Cuadro 1 presenta una estimación preliminar del impacto económico del terremoto del 13 de enero sobre la economía nacional, aunque, como podrá observarse, los datos no reflejan los efectos directos e indirectos, debido a que todavía no se cuenta con la información necesaria para hacer esas estimaciones. Con todo, aun con esa salvedad, pueden utilizarse los datos siguientes para

8. Vćasc, por cjemplo, CEPAL, 1973; CEPAl, 1982; CEPAL, 1986; CEPAI., 1908.

9. Véasc CEPAL, 1991.

10. Pesc a que sc han hecho diferentes críticas validas a la metodologia utilizada por la CEPAL, su clasificación de efectos continúa siendo válida para analizar el impacto cconómico de los desastres.

11. Ídem.

12. Ibid.

13. Ibid.

14. Ibid.

15. Ibid. 
tener una visión aproximada de los efectos económicos del sismo. Vale la pena destacar antes dos aspectos importantes: primero, la inclusión de los ingresos perdidos por el fallecimiento de víctimas $y$, segundo, el que todavía no se cuenta con datos confiables para cuantificar los costos sobre los sectores productivos.

En cuanto al primer aspecto, de lo que se trata es de presentar un estimado del costo que representa para un grupo familiar la muerte de uno de sus miembros, en términos de reducción de ingresos durante los años restantes de su vida productiva, los cuales se conocen como Años de Vida Saludable Perdidos (AVISA). Esta metodología se ha utilizado principalmente para estimar los costos económicos de la violencia, pero también resulta útil para el hecho que nos ocupat ${ }^{16}$. En el segundo caso, debemos considerar que no valorar el efecto sobre los sectores productivos implica dejar fuera una importante proporción de los costos económicos del desastre. Por ejemplo, en el Mitch, el daño en los sectores productivos llegó a representar cerca de un 70 por ciento del total de los $\operatorname{costos}^{17}$; consecuentemente, la cifra global que se presenta debe ser considerada con las debidas precauciones.

Los costos totales, reflejados en el cuadro, ascienden a 8368.1 millones de colones, equivalentes a 956.43 millones de dólares, lo cual equivale aproximadamente a un 7.6 por ciento del producto intemo bruto del año 2001. Como puede apreciarse, buena parte de los gastos están concentrados en el área de vivienda e infraestructura, tal como nomalmente sucede en los desastres provocados por terremotos. De hecho, sólo la reconstrucción de viviendas y la vivienda provisional estarían representando más de un $\mathbf{4 5}$ por ciento del total de los costos reflejados en el cuadro (esto sin considerar los costos indirectos, asociados a la vivienda provisional). Otros costos significativos son los asociados al mantenimiento de la salud de los damnificados, los cua- les pueden llegar a representar un poco más del 27 por ciento de los costos presentados en el cuadro.

Si agregáramos los costos económicos asociados a los sectores productivos, para los cuales todavía no se dispone de datos, la cifra se incrementaría notoriamente, tanto por los efectos primarios del terremoto, como también por sus efectos secundarios. Si consideramos que una cifra estimada moderada rondaría los 7000 millones de colones, tendríamos que los costos del terremoto prácticamente se duplicarian y fácilmente alcanzarían un 13 ó 14 por ciento del producto intemo bruto. Por lo demás, aunque así fuera, los costos del terremoto del 13 de enero del 2001 estarían muy por debajo de los costos asociados al terremoto del 10 de octubre de 1986, los cuales se estimaron en aproximadamente un 30 por ciento del PIB ${ }^{18}$. En lo fundamental, esto obedece al hecho de que el terremoto de 1986 focalizó sus daños en el área metropolitana de San Salvador, centro neurálgico del pais, donde se concentra el grueso de la actividad económica, social y política. El terremoto del 13 de enero tuvo efectos más extensos en todo el país y no causó daños mayores en la ciudad de San Salvador, lo cual explica su menor impacto económico relativo.

Sin embargo, tampoco debe obviarse el hecho de que, aunque las pérdidas puedan ser menores en términos cuantitativos, el terremoto afectó a grupos de población con muy poco capital acumulado, lo cual implica que las pérdidas (por modestas que parezcan) pueden, en algunos casos, ser aproximadamente de un 80 ó de un 100 por ciento de lo que poseían los sectores perjudicados. Esto nos lleva a la necesidad de considerar que el impacto siempre es relativo a la capacidad de recuperación, pues mientras para unos sectores una pérdida de, por ejemplo, 25000 colones, puede ser poco significativa, para otros puede implicar perder todo lo que se poseía. Así, pues, aunque este terremoto podría arrojar un balance de pérdidas in-

16. Véase Bobabilla, et al., 1995.

17. CEPAL, 1998.

18. CEPAL, 1986. 
ferior al terremoto de 1986, no quiere decir que su impacto no haya sido mayor, ya que ha afectado a un mayor número de población integrado por sec- tores rurales, sumidos en situación de extrema pobreza, asentados, principalmente, en el eje cafetero ubicado, en la cadena volcánica central del país.

\section{Cuadro 1}

Cuantificación de costos provocados por el terremoto del 13 de enero

\begin{tabular}{|c|c|c|c|c|}
\hline Rubro & $\begin{array}{l}\text { Costo } \\
\text { (En colones) }\end{array}$ & $\begin{array}{l}\text { Cantidad } \\
\text { (En colones) }\end{array}$ & $\begin{array}{c}\text { Total } \\
\text { (En colones) }\end{array}$ & $\begin{array}{c}\text { Total } \\
\text { (En colones) }\end{array}$ \\
\hline \multicolumn{5}{|l|}{ Vivienda } \\
\hline Reconstrucción de vivienda rural & 31425 & 92080 & 2893614000 & 330698743 \\
\hline Reconstrucción de vivienda urbana & 225000 & 455 & 102375000 & 11700000 \\
\hline Costo de pérdida de mobiliario y equipo & 1620 & 222085 & 359719958 & 41110852 \\
\hline $\begin{array}{l}\text { Gasto por habitante en vivienda provisional } \\
\text { Infraestructura }\end{array}$ & 743 & 1114011 & 827932975 & 94620911 \\
\hline Edificios públicos & 850000 & 856 & 7276000000 & 83154286 \\
\hline Iglesias & $500(0) 0$ & 318 & $159(000)(0) 0$ & 18171429 \\
\hline Muelles & 75000 & 43 & 3225000 & 368571 \\
\hline Medio ambiente & & & & \\
\hline $\begin{array}{l}\text { Ha. bosque secundario } \\
\text { Salud }\end{array}$ & 363 & 800 & 290640 & 33216 \\
\hline $\begin{array}{l}\text { Gasto en medicamentos por damnificado } \\
\text { primario }\end{array}$ & 476 & 1114011 & 5300464.34 & 60576735 \\
\hline \multicolumn{5}{|l|}{ Gasto en saneamiento, agua, letrinas, } \\
\hline $\begin{array}{l}\text { Gasto indirecto en salud por damnificado } \\
\text { Disposición tratamiento y recuperación de }\end{array}$ & 1022 & 1114011 & 1138853445 & 130154679 \\
\hline víctimas & 1044 & 4440 & 4635360 & 529755 \\
\hline $\begin{array}{l}\text { Ingresos perdidos } \\
\text { Educación }\end{array}$ & 107389 & 726 & 77964414 & 8910219 \\
\hline \multirow{2}{*}{\multicolumn{5}{|c|}{$\begin{array}{l}\text { Costo de usar escuela como albergue } \\
\text { Sectores económicos }\end{array}$}} \\
\hline & & & & \\
\hline Agricultura & n.d. & 9000000000 & 9000000000 & 102857143 \\
\hline Pesca & n.d. & n.d. & & \\
\hline Ganadería & n.d. & n.d. & & \\
\hline lndustria & n.d. & n.d. & & \\
\hline Financiero & n.d. & n.d. & & \\
\hline Comercio & n.d. & n.d. & & \\
\hline Costos totales & & & 8.368821381 & 956436729 \\
\hline
\end{tabular}

Fuente: Elaboración propia con base en los costos unitarios utilizados por CEPAL (CEPAL, 1998) e informes oficiales de evaluación de daños.

\subsection{Perspectivas de la economía salvadoreña frente al desastre}

Desde antes del impacto del terremoto, El Salvador se debatía en un escenario que, a grandes rasgos, se caracterizaba por dos aspectos principales: una reducción de las tasas de crecimiento eco- nómico y la profundización de los desequilibrios macroeconómicos (especialmente el déficit de la balanza comercial y las finanzas públicas). De hecho, los principales planteamientos del gobierno apuntaban hacia la adopción de políticas de reactivación económica; es en este marco que se ubi- 
caban las propuestas gubemamentales de reactivación del sector agropecuario, de inversión en la zona norte del país y, más recientemente, la propuesta de dolarización económica. De acuerdo al presidente Flores, con esta última medida se generarían reducciones en las tasas de interés y se estimularía la inversión, la producción y el empleo. El escenario de pos terremoto cambia radicalmente este escenario, pues ahora la principal preocupación ya no estriba en cómo incrementar las tasas de crecimiento o como erradicar los desequilibrios macroeconómicos básicos, sino más bien en cómo se enfrentan las ingentes necesidades económicas y sociales suscitadas por el desastre.

Asimismo, lo anterior no implica que las prioridades deban estar en función de volver a la situación previa al terremoto, tal como lo propusiera a pocos días del terremoto el presidente Flores, sino más bien en cómo se aprovechan las oportunidades para implementar programas de desarrollo que no sólo persigan la reconstrucción de lo destruido, sino más bien la construcción de un país más justo y equitativo. Algunos elementos importantes por considerar tienen que ver con el sector cafetalero y la redefinición de los polos de crecimiento económico.

(a) Impacto sobre el sector cafetalero. Este sector ha sido uno de los más afectados por el terremoto del 13 de enero, debido a que éste último hizo sentir su fuerza de manera especial en zonas montañosas, donde se desarrolla el cultivo del grano. El terremoto destruyó instalaciones agroindustriales de procesamiento del grano (conocidos como beneficios de café) y provocó derrumbes y deslizamientos en terrenos cultivados. De acuerdo al Consejo Salvadoreño del Café, se espera una reducción de aproximadamente 33 por ciento en la cosecha anual, lo cual implica una reducción de aproximadamente 900 millones de colones, con la consecuente reducción en la demanda de mano de obra estacional, la cual, según las mismas fuentes, se estima en cerca de 40000 puestos de trabajo perdidos.

Pero más allá de la recuperación de la producción de café y el restablecimiento de la economía tradicional de las zonas devastadas, debe valorarse si en realidad esta era ya de por sí una siluación deseable, especialmente si se considera que el café es una actividad económica donde la mayor parte del empleo generado es de carácier temporal y con remuneraciones que se encuentran por debajo de la línea de pobreza extrema. Por si fuera poco, el café ya no resulta una opción viable para los mismos productores, debido a los altibajos en los precios internacionales de la década de 1990, mismos que han mantenido al sector en una situación de crisis permanente. En este contexto, queda abierta la necesidad de buscar estrategias que, aprovechando la coyuntura del terremoto, pudieran sentar las bases para una verdadera transformación de la economía salvadoreña en una economía productiva y mejor insertada en el mercado mundial.

(b) Retraimiento económico y redefinición de polos de crecimiento. Otros efectos de consideración son los "secundarios", pues se espera una reducción significativa en las expectativas de crecimiento de la producción y un empeoramiento de los desequilibrios macroeconómicos, que venían arrastrándose desde antes del terremoto. Después de un desastre como el que ha padecido el país, el aparato productivo se ha visto afectado, tanto por una reducción de la capacidad de procesamiento agroindustrial del grano de café, como por daños en cerca de un 35 por ciento en diferentes subsectores de la industria salvadoreña. Por otra parte, cabe esperar que las importaciones se incrementen como resultado de la implementación de los programas de construcción de vivienda e infraestructura, pero las exportaciones no crecerán tanto como se espera, debido a los daños en el sector cafetalero. Consecuentemente, podría esperarse un incremento en el déficit de la balanza comercial para finales de este año.

Por el lado de las finanzas públicas, también podría haber un efecto importante, en la medida que el gobierno se vea obligado a incrementar su gasto, al mismo tiempo que experimenta un crecimiento más lento de sus ingresos. El gasto se incrementaría, ya sea porque el gobierno utiliza sus reservas o porque contrata mayores empréstitos intemacionales, los cuales, a su vez, lo obligan a incrementar el gasto en concepto de servicio de la deuda; por su parte, los ingresos tributarios no crecerían tan rápidamente, porque la producción tampoco to hará. Sin embargo, no todos los efectos secundarios son negativos, siendo que también cabe esperar que los procesos de consirucción de vivienda e infraestructura estimulen el crecimiento del sector construcción, minería y del comercio de materiales de construcción. Incluso, podría esperarse un incremento de los flujos de divisas del exterior, ya sea en concepto de remesas familiares o de donaciones, producto de la solidaridad de los 
familiares de los damnificados residentes en el exterior.

Una interrogante importante en este marco es hasta qué punto los programas de construcción de vivienda e infraestructura (e inclusive de recuperación del sector cafetalero) representan una opción para reducir la vulnerabilidad que llevó a que el pasado terremoto se convirtiera en un desastre. Ya antes el país ha conocido épocas de gran expansión de la industria de la construcción y gran bonanza de la actividad cafetalera, pero ninguna de ellas ha sido suficiente para superar la situación de pobreza y vulnerabilidad estructural en la que se debate la mayor parte de la población salvadoreña. Sin pretender negar la importancia de la construcción de viviendas, cabe señalar que ésta poco cambiará la situación económica de los beneficiarios, si éstos no están integrados en un proyecto de nación, que tenga como propósito esencial disminuir las desigualdades sociales más hirientes.

\section{Impacto social}

En países como El Salvador, los desastres, sin importar su naturaleza, tienen la capacidad inigualable de poner en evidencia el verdadero sentido de la palabra subdesarrollo. Viviendo de modelos poco apropiados para la gestión de sus recursos naturales y humanos, El Salvador y sus iguales en el conglomerado de naciones pobres resienten con especial dramatismo el momento preciso en el que las fuerzas de la naturaleza — ayudadas o no por voluntad humana- se alzan, como azarosa sentencia, sobre la vida de la colectividad.

De esta manera, la tragedia finalmente sobrevino en forma de terremoto y el país entero deberá enfrentarla con todas sus fuerzas. Esta frase recoge los dos elementos que caracterizan el legado de un desastre como el que la población salvadoreña sufrió el 13 de enero del 2001. Por un lado, la completa incapacidad del ser humano para predecir siquiera el momento en el que la amenaza de las fuerzas de la naturaleza se manifiesta. Por el otro, el instantáneo y obligado compromiso de la sociedad para aprender a controlar los factores que multiplican los efectos de un desastre sobre su desarrollo y, en el mejor de los casos, para asegurarse de que jamás se volverá a someter a la población a tal devastación y zozobra. 
fundamentales de la catástrofe (gobiemo central y municipal, empresa privada, medios de comunicación masiva) en la construcción de estos nuevos caminos? ¿Qué espacios de participación se han instituido para la población? ¿Los planes futuros de prevención y respuesta a los desastres incluyen estas contribuciones y estos espacios de participación? Esas son algunas de las preguntas fundamentales que guiarán este apartado. También intentaremos evaluar la respuesta concreta que dieron las autoridades después del terremoto del 13 de enero. Finalmente, haremos un análisis de la cobertura periodística del desastre.

\subsection{La sociedad frente al desastre}

Como ya mencionamos, lo esencial de un desastre es su capacidad para provocar un "rompimiento extenso y casi completo de todos los procesos sociales, de la estructura social $[\ldots]$ y de las interacciones primarias y secundarias", que configuran la vivencia de una sociedad ${ }^{14}$. Esta situación se constata tanto en el plano individual como en el colectivo. Por una parte, las personas o familias que han sufrido la pérdida de sus hogares, de sus negocios, de sus lugares de trabajo, o de seres queridos; que además han tenido que modificar sus rutas y mecanismos de movilización a causa de la destrucción de la infraestructura vial; que se han visto parcial o totalmente privadas de los servicios básicos; todo ello constituye una alteración sensible en la manera de enfrentarse a los problemas cotidianos, en la lucha cotidiana por la supervivencia.

Por otra parte, tenemos los efectos directos $\mathrm{c}$ indirectos que el estado de desastre genera en las prioridades de las instituciones gubernamentales, en los sectores tradicionalmente considerados centrales para la productividad nacional, en las relaciones que se establecen entre las instituciones no gubernamen- tales, la sociedad civil organizada, la ciudadanía y el gobiemo. Todo ello representa, desde un plano fundamentalmente institucional, una reestructuración forzosa de la forma en que se administra la vida de una nación. Además, en países como El Salvador, la posibilidad que se abre para que sean las urbes las que absorban la mayor parte del impacto de los desastres, al convertirse en focos de atracción para quienes deberán abrirse nuevos espacios de supervivencia, también implica una modificación del panorama social al cual se enfrenta la población después de un desastre.

En la reconstitución de esos procesos sociales es donde se verifica la efectividad o inoperancia de la respuesta de la sociedad ante situaciones críticas. En El Salvador, tal inoperancia se refleja en la virtual ausencia de esfuerzos, tanto de preparación previa de la población en situación de riesgo, como de mitigación de las consecuencias negativas que dejan este tipo de acontecimientos. La excesiva atención que el gobiemo de Francisco Flores dio a una de tantas etapas de la respuesta a un desastre, la atención a las víctimas mortales, responde a esa falta de atención que se ha dado a los dos procesos previos mencionados: la preparación y la mitigación. Y, a la larga, la población misma reaccionó con tanto desconocimiento de la situación como el mismo presidente y su equipo de gobiemo. No se puede negar, eso sí, que la ciudadanía no organizada dio muestras de poseer un espíritu especial de solidaridad con el que más lo necesila. Su respuesta consistió, en un primer momento, en ofrecer con la mayor agilidad posible ayuda a quienes no podrían sobreponerse a la crisis por sí solos.

Sin embargo, y sin la intención de menospreciar el apoyo brindado por la población durante los primeros días de la crisis"2", el hecho es que la organización de todo el voluntariado no ha sido la mejor.

19. H. Rodríguez y M. Troche, "Preparación y miligación en Puerto Rico: un análisis organizacional", Revisła Desastres y Sociedad 2 (enero-julio 1994) 27.

20. Para nadie pasó desapercibido que, durante los primeros días de la tragedia, muchos de los refugios para damnificados se mantuvieron gracias a la colaboración de voluntarios. Ver La Prensa (íráfica, 15 de enero, p. 10; 17 de enero, p. $4 ;$ y 19 de enero, p. 4. 
El caso del derrumbe en la urbanización La Colina ha sido una clara muestra de esta deficiente organización: los miles de personas que se ofrecieron para ayudar de alguna manera, lo hicieron sin saber claramente qué hacer o, en el mejor de los casos, sólo para colaborar en lo que la mayoría gastaba sus fuerzas: remover tierra y escombros en busca de supervivientes o cuerpos reconocibles. Al final, el voluntariado fue mucho, pero luvo que pasar algún tiempo para que éste comenzara a dar frutos que fueran más allá de estas acciones.

En el fondo, esta situación es la manifestación más palpable de la ausencia de estrucluras organizativas mínimas, que le permitan a la ciudadania identificar, priorizar y movilizarse en función de unos objetivos comunes. Así, parte de la vulnerabilidad social de la que tanto se habla en estos días -ésa que ha hecho que unos sufran con mayor dramatismo el terremoto que otros - tiene su origen en esta carencia. De más está decir que, de haber contado con esas estructuras mínimas, se habría facilitado otro de los elementos que intervienen en la etapa de respuesta frente a los desastres: la organización del recurso humano disponible $^{21}$.

Quiérase o no, todas las sociedades del mundo conforman una red de instituciones - sin importar su naturalezaque tienden a sistematizar el horizonte de expectativas y demandas a las cuales se les debe dar respuesta. De la relación que se establezca entre esas instituciones y, más importante todavía, del alcance que posean en virtud de los intereses de la población a la cual se deben, depende, en última instancia, la manera en que se dé respuesta a esas necesidades más o menos sistematizadas ${ }^{22}$. En el caso de El Salvador, el gobierno, como red institucional más importante, no ha podido alcanzar un perfil aceptable al respecto. En su lugar $-y$ con evidentes limitaciones-, algunas instituciones no gubemamentales han pretendido salir adelante para ofrecer una visión más integrada de determinadas problemáticas nacionales.

En todo caso, El Salvador no ha podido superar la excesiva atomización de la cual es víctima el conjunto de instituciones que gravitan en el panorama social actual. Por el contrario, esa red de inslituciones que inevitablemente posee se vincula sólo coyuntural y precariamente. Desde esta perspectiva, es válido preguntarse sobre la capacidad que tendrían las actuales organizaciones no gubernamentales para asimilar una posición estratégica dentro de un plan que defina las nuevas rutas que el desarrollo nacional debería seguir. Buena parte de esas organizaciones hicieron un buen trabajo movilizando ayuda hacia donde el COEN y CONASOL no pudieron. Pero lo más importante, es decir, la capacidad de esas instituciones para dotar a la población de unos mecanismos mínimos que le permitan desarrollar sus propios medios de reparación y de intervención en situaciones de riesgo, todavía no ha sido convenientemente abordado desde el trabajo de las mismas.

21. Francoise Coupé, en su artículo "Políticas urbanas y participación frente a los desastres" (Revisıa Desastres y Sociedad 2 (cncro-julio 1994) 72, sosticnc que uno de los principales factores que promucven una respucsta efectiva de parte de la ciudadanía en siluaciones de desastre es la existencia previa de organizaciones comunitarias, ya sca que funcionen como "redes informalcs", "organizaciones de hecho", organizacioncs "doladas de reglamentos y normas" u otro tipo de instiluciones que, pese a su distancia del contexto inmediato de la comunidad, son capaces de retomar sus exigencias y expectativas

22. "Hay, por lo tanto, una conexión estrecha entre 'la estructura institucional' problematizada por cl desastrc, y las actividades oricntadas a su restitución". F. Plicgo Carrasco, "Estratcgias de desarrollo social cn situaciones de desastres", Revista Desastres y Sociedad 2 (cncro-julio 1994) 53. 
Así, sin un aparato sólido y confiable de organismos que hagan de la asociatividad civil un arma contra la excesiva vulnerabilidad a la cual se enfrenta la población, lo que más resalta, a la hora de enfrentar desastres como el ocurrido el 13 de enero, es la increible falta de previsión de la cual adolece el país entero. De esta suerte, ante la pregunta global sobre la reacción de la sociedad frente al sismo recién pasado, la respuesta debe tomar en cuenta, además de la encomiable movilización voluntaria de un enorme contingente de ciudadanos desinteresados, esa deficiencia en la organización de la población en función de unos intereses comunes, que se manifiesta y se reproduce individual y colectivamente.

\subsection{Los gobiernos locales}

Sin duda alguna, dentro de los gobiernos municipales se pueden encontrar algunos verdaderos ejemplos de respuestas exitosas ante la crisis desatada el 13 de enero. Pese a que durante años han sido señalados como organismos ineficientes en la administración local, el terremoto recién pasado puso a prueba toda su capacidad para organizar, en pequeño, lo que debería configurarse como la respuesta a la crisis que se desató a lo largo y ancho del territorio nacional. Y aunque la misma situación que se configuró después del terremoto no deja lugar a generalizaciones, el hecho es que se ha demostrado con creces la necesidad ineludible de trabajar desde lo local para establecer un mejor control —con participación- de los procesos de desarrollo social que, en esta ocasión, se refieren a la respuesta frente a situaciones de desastre. Sin embargo, dos han sido los elementos que ensombrecieron esta labor en aquellos municipios donde la respuesta al desastre fue más notable: primero, el marcado aislamiento entre la iniciativa gubernamental y la municipal y, segundo, la creciente politización que sobre esta ineludible relación se ha adueñado de algunos municipios del país.

Seguramente, mucho se podrá abonar al debate sobre las intenciones últimas del gobierno central al dejar a su suerte a buena parte de las alcaldías del país, en el momento más crítico del terremoto.
Pero no es ese enfoque el que retomará este apartado. Por el contrario, de lo que se trata es de reflexionar en torno a la manera en que este aislamiento es reflejo y efecto de la visión que se tiene del poder local, en relación con los planes de prevención y respuesta a los desastres.

Una semana de ocurrido el terremoto, CONASOL y el gobierno de Flores decidieron incluir a los municipios en el mecanismo de administración de fondos para la remoción de escombros. Algunos creyeron ver en el "gesto" una manera de reconocer el error cometido. Finalmente, la estructura organizativa centralizada con que se contaba para dar respuesta al terremoto - de cuyo trabajo dificilmente se podía obtener referencia en su sede, la Feria Internacional- le apostaba a la gestión municipal como ente confiable para el desarrollo del plan de reconstrucción nacional.

Nada más lejos de la realidad. Fundamentalmente, porque ese llamado a la participación no era más que la imposición de una serie de procedimientos administrativos, que no cubrían todas las necesidades registradas por algunos municipios -a veces, los más afectados - a causa del sismo. La casi inmediata reacción de las municipalidades, incluyendo a aquellas administradas por el mismo partido de gobierno, fue una confirmación de este craso error: rechazar tajantemente el uso del fondo que se les otorgaría para la remoción de escombros.

En este sentido, lo que resulta evidente en la concepción que el gobierno central posee de la intervención en periodos de crisis postdesastres es que, primero, no hay lugar para "estructuras menores", cuya capacidad técnica, material y humana se ve superada a la menor crisis de alcance nacional; segundo, tampoco se logra establecer una relación estable entre gobierno central y local, de tal forma que el primero facilite la sostenibilidad de la gestión del último ${ }^{23}$.

¿Qué le hace falta al gobierno de Flores para darse cuenta de la importancia estratégica que poseen los gobiernos municipales $y$, en fin, las instituciones que apoyan la organización local, en la

23. De hecho, Gustavo Wilches-Chaux (Guía de La Red para la gestión local del riesgo, La Red, 1998) sosticnc que el éxito de la incorporación de actores locales en las polílicas y programas de gestión de riesgo depende fundamentalmente del grado de participación que se les otorguc (que debe constituirse en una "manera de ser") y de las posibilidades de autogestión y sostcnibilidad que se les ofrezcan para intervenir efectivamente cn su localidad. 
respuesta y prevención de desastres? Probablemente, una buena dosis de realismo y de compromiso serio con el desarrollo, en igualdad de condiciones para la población. Realismo, no sólo porque se debe empezar a trabajar, de una vez por todas, en la reducción de la vulnerabilidad a la cual está sometida la mayor parte de la población. También le hace falta realismo para aceptar que la mayoría de las municipalidades adolece de la capacidad para movilizar sus recursos, en aras a solucionar los problemas que les competen. Es hacia ahí donde el gobierno central, la empresa privada, las instituciones no gubernamentales y la comunidad internacional deben enfocar sus aportes.

En definitiva, este débil lazo que une el trabajo de las municipalidades con el del gobierno cen-

tral viene a poner en peligro la planificación - si es que se la puede llamar así-, que se ha pucsto en marcha para iniciar la reconstrucción nacional. El problema, entonces, no sólo radica en que de esa planificación se debe dar cuenta en el mediano plazo, cuando El Salvador presente su propuesta de reconstrucción al Grupo Consultivo de Madrid. Lo que no debe escapar del análisis es el hecho de que el gobierno mismo, sea política, ideológica o administrativamente, atenta contra una de las bases de la gobernabilidad que tanto se requiere para salir medianamente solvente de una situación como la que se vive actualmente: la relación de complementariedad entre los poderes y las instiluciones del Estado, incluyendo a los municipios ${ }^{24}$.

\subsection{El gobierno central}

El terremoto del 13 de enero no sólo vino a mover el suelo salvadoreño, literalmente hablando, sino que también puso a prueba la frágil institucionalidad que se había alcanzado, así como las propuestas económicas, políticas y sociales impulsadas por el gobierno y su capacidad de respuesta ante situaciones de desastre. Para este apartado del gobierno central, se hizo un sondeo de lo que algunos medios de prensa informaron sobre las actividades realizadas por instituciones como el Órga- no Ejecutivo, COEN y CONASOL. Se analizó la información difundida por los periódicos con más circulación del país (La Prensa Gráfica y El Diario de Hoy) durante la semana del 14 al 21 de enero.

Improvisación, asombro, desconcierto, visceralidad fueron algunas de las respuestas que se dieron ante la catástrofe, en todos los niveles de autoridad. El gobierno, siguiendo el mandato de "reconocer a la persona humana como el origen y el fin de la actividad del Estado", intentó dar respuesta a las necesidades de los salvadoreños en los momentos de crisis, pero ¿qué tipo de respuesta dio? ¿Fueron efectivos la planificación y el seguimiento de los planes de emergencia para estos casos? ¿La respuesta fue concertada y responsable? Es indudable que, en momentos de crisis social, sobre todo, desaladas por fenómenos naturales "imprevistos", las respuestas nunca parecen ser suficientes, debido a la magnitud de los daños ocurridos -lanto materiales como humanos-, pero ello en realidad no exime al gobierno de cumplir eficazmente ese primer mandamiento de la Constitución.

Un país como El Salvador, en el que la vulnerabilidad en todos los ámbitos de la vida nacional está presente permanentemente, obliga a estar preparados para eventos como el del día 13. La frase "el terremoto nos encontró desprevenidos" no es válida cuando sólo en el siglo recién pasado se registraron cinco movimientos telúricos de gran intensidad y cuando, apenas en 1998, la tormenta tropical Mitch provocó fuertes daños en la zona del Bajo Lempa. Esto sin contar los años de guerra que mantuvieron al país en permanente estado de alarma. La frase "el terremoto nos encontró desprevenidos" no es respuesta para todas aquellas familias que han perdido a uno o más de sus miembros y para las miles de personas que han perdido sus casas y bienes.

Por lo demás, la presencia del presidente Flores, en los dias posteriores a la catástrofe, fue mínima y esporádica. Así las cosas, es claro que Flores debe tener más protagonismo, capacidad de

24. G. Wilches-Chaux, idem, p. 133. 
ejecución y acción en una situación de crisis. Sin embargo, su desempeño ha reforzado la idea de que el gobiemo de El Salvador no tiene líneas claras ni mecanismos concretos que le permitan actuar eficazmente en una situación de desastre. El desempeño, tanto del COEN como de CONASOL, es también aleccionador sobre las deficiencias gubernamentales apuntadas.

El COEN, a pesar de haber sido designado para "organizar y dirigir en forma coordinada las acciones tendientes a prevenir desastres o calamidades públicas y disminuir sus efectos" ${ }^{25}$, tuvo una presencia mínima en el contexto del terremoto y sus secuelas inmediatas. Solamente los días miércoles 17 y sábado 20 aumentó su presencia como fuente informaliva. Sin embargo, este repunte en las tareas de información no significa que su actividad aumentara en relación a los días anteriores o que la información manejada fuera de la mejor calidad. Por ejemplo, desde el domingo 14, varios medios de prensa mencionan la discrepancia entre los datos oficiales del COEN y los de los cuerpos de socorro y las alcaldías. El miércoles 17 se informa la poca aclualización de sus registros, en comparación con los de otras instituciones (cuerpos de socorro y municipalidades).

La misma discrepancia se señala el viemes 19 de enero, cuando el COEN no informa de nuevas víctimas de la catástrofe, mientras que otras fuentes sí lo hacen. Estas "irregularidades" obligan a la siguiente pregunta: ¿qué nivel de credibilidad institucional y social tendrá "el único organismo autorizado para dar cifras oficiales", si esas cifras se contradicen o no están actualizadas? Para ahondar más en lo anterior, es pertinente traer a cuenta que, el mismo miércoles 17, los diputados de la Asamblea Legislativa calificaron el informe de daños del COEN de "escueto". El director de la institución, Mauricio Ferrer, trató de justificarse diciendo que "sólo era un repor- te preciso para informarles sobre las necesidades de recursos económicos para la reconstrucción".

Los estatutos del COEN establecen que uno de sus principales objetivos es la prevención de desastres. ¿Qué tipo de acciones preventivas había planificado el COEN para solventar una situación de crisis como la del 13 de enero? ¿Estaba preparado el COEN para responder a una situación como la que vivió el país después del terremoto? ¿De qué manera el COEN ha disminuido la magnitud de los hechos, si Mauricio Ferrer aduce que su función no es la de repartir víveres, sino sólo de registrar daños?

Estas preguntas surgen ante la escasa información que fluye hacia fuera de este organismo. Son resultado, además, de la poca planificación y de la nula capacidad de gestión informativa. Probablemente, este es el motivo por el cual su presencia y las acciones realizadas no están plasmadas en la cobertura informativa que hicieron los medios de prensa de la tragedia. Como quiera que sea, el silencio institucional - concretado en su poca presencia en los dos diarios analizados-, unido a la falta de claridad en las funciones de los organismos gubermamentales, es peligroso. Dicho silencio informativo puede considerarse como expresión de su poca capacidad de gestión y organización.

Un día después del terremoto, el gobiemo de Flores conforma CONASOL con un grupo de "notables empresarios". La principal diferencia entre este comité y el conformado en 1986 por el entonces presidente José Napoleón Duarte, es que en aquel entonces la empresa privada era un sector ajeno al gabinete de gobiemo. Ahora, el coordinador de la CONASOL, Roberto Murray Meza, es el primer designado a la presidencia por el partido oficial y una de las figuras más influyentes en el mismo. Otros de los miembros de la comisión son Ricardo Simán, presidente de la Asociación Nacional de la Empresa

25. Programa de emergencia Secretaría Ejecutiva de Emergencia Nacional. htıp://minter.gob.sv/coen/principal. 
Privada (ANEP), y Héctor Vidal, miembro de la Cámara Salvadoreña de la Construcción (CASALCO).

Muchas han sido las críticas que la conformación de CONASOL ha provocado, pero antes de revisarlas, se presentará la genealogía de la configuración de esta nueva "institución". El sábado 13 de enero, unas horas después del terremoto, el presidente Flores se dirigió en cadena nacional a la población salvadoreña, expresando su pesar y las acciones inmediatas que su gobiemo estaba a punto de realizar. Ese momento fue aprovechado para pedir a todos los "países amigos" cualquier tipo de ayuda, puesto que el país estaba en situación de emergencia.

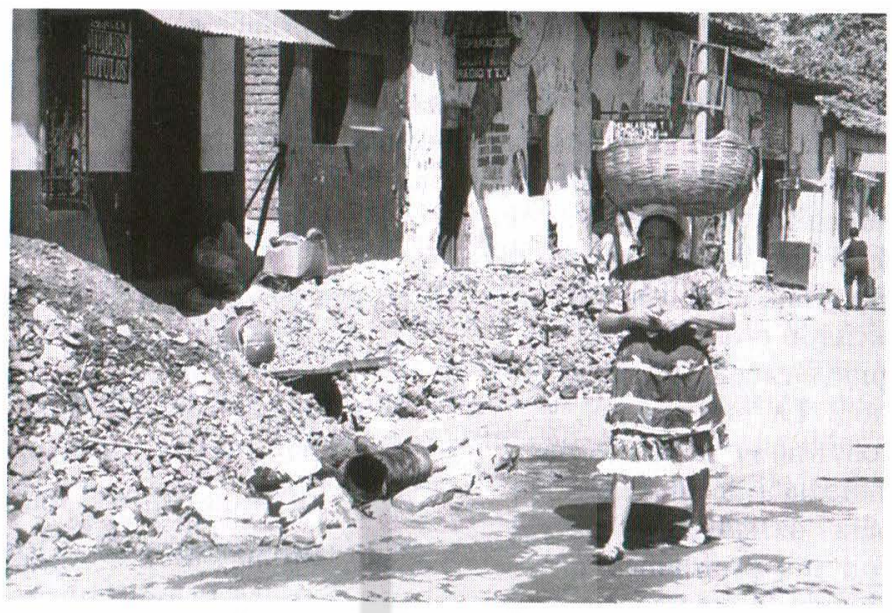

El domingo 14 de enero, el presidente Flores, en conferencia de prensa, presentó a la población -preocupada en ese momento por el rescale de las víctimas - a un grupo de miembros de la cúpula empresarial del país, encabezados por Roberto Murray Meza. El presidente Flores anuncia la conformación de CONASOL. Su función: "administrar" las donaciones nacionales e internacionales para las víctimas del terremolo. Para esto, CONASOL abrió cuentas bancarias, puso bodegas de acopio en la Feria Internacional, estableció procedimientos de distribución de ayuda y contrató empresas auditoras.

Después de una serie de denuncias por el atraso en la distribución de donaciones, tanto de los medios de comunicación, como de miembros de los concejos de los municipios más afectados y de otros seclores de la sociedad civil, el domingo 21 de enero, los miembros de CONASOL anuncian un cambio en sus mecanismos de distribución: tomarán como intermediarios principales a los gobiernos locales. Pese a ello, las denuncias no se deluvieron, incluso ahora que el gobierno ha anunciado el inicio de la etapa de reconstrucción.

¿Por qué se tuvo que formar una comisión especial, cuando es obligación exclusiva del Estado, a través del COEN, satisfacer necesidades provenientes de guerra, de calamidad pública o de grave perturbación del orden ${ }^{26}$ ? El respeto a la institucionalidad en cualquier situación, sobre todo en caso de desastres, es primordial para poder responder de ma-

nera adecuada a las necesidades y mantener la estabilidad de la población. Una institución como el COEN tiene, por ley, que estar más capacitada que un grupo de notables empresarios para responder a la emergencia, suscitada por el terremoto. Obviamente, ello no es así. El terremoto del pasado 13 de enero ha puesto en evidencia el mal del que padece, en general, la gestión gubemamental: ineficiencia, descoordinación y poca fluidez en la transmisión de información para la población. ¿Cuántas catástrofes más debe padecer la sociedad salvadioreña para que las autoridades formulen planes de prevención y den una respuesta efectiva a los problemas de vulnerabilidad del país?

\subsection{Los medios de comunicación}

En momentos de crisis, la importancia de la información se hace mucho más grande. Es por eso que la población, asustada por los movimientos telúricos y sin superar el pánico posterremoto, redobló sus consultas en las televisoras, los periódicos y la radio después del 13 de enero. Para asegurar su aparición en los listados de ayuda, mucha gente de cantones, caseríos y colonias incluso acudió, en primera instancia, a algún medio de comunicación para que sus reclamos fueran oídos por las autoridades correspondientes. El que no aparecía en los medios, era como si no existiera (mal de las sociedades informatizadas). Por casos como este, es que se hace imporlante evaluar la labor que desempeñaron los medios de comunicación una vez declarada la emergencia nacional.

26. Artículo 167, inciso 4, Constitución de la República de El Salvador. 
Después del 13 de enero, uno de los primeros retos para los medios de difusión fue tratar de coordinar y contactar a todo su personal para averiguar la magnitud de los daños lo más inmediatamente posible. Las estaciones Cuscatlán y YSKL fueron las primeras en salir al aire después del sismo y una hora después lo hicieron otras radios y algunos canales de televisión. La radio, pues, se convirtió en la fuente más inmediata de información para los salvadoreños $y$, con los problemas propios de la emergencia, se encargó de dar las primeras informaciones del desastre. Los medios (y la nación entera) lardaron más de dos días en darse cuenta del alcance que había tenido el terremolo, no sólo en Santa Tecla, sino en algunas regiones más apartadas de San Salvador.

En cuanto al tratamiento y cobertura periodística, la televisión y los periódicos se han destacado más que la radio, en los últimos cinco años. Eso se reflejó en esta coyuntura. Aunque la radio fue la primera en resolver sus problemas de transmisión, después del terremoto del 13 de enero, la labor informativa fue mucho más amplia en los otros medios de difusión (por su disponibilidad de recursos logísticos y de personal para recoger noticias, y en ciertas ocasiones por su calidad).

\subsubsection{La televisión: la tragedia que vimos}

Era evidente que no estaban preparados para una catástrofe como el terremoto del 13 de enero. No tenían un plan de contingencia y reaccionaron más por instinto que otra cosa. Su trabajo fue más fruto de la voluntad de las personas que de una planificación instilucional. No nos referimos aqui a las instituciones de gobierno (COEN, CONASOL y conexos), sino a los noticieros de televisión. Este es un breve análisis de la forma en que éstos reaccionaron ante el sismo, la cobertura inicial y cómo ésta fue derivando hacia esquemas sensacionalistas, descriptivos o críticos.

Aunque es justo reconocer la notable labor informativa que hizo la radio, sobre todo la $Y S K L$, en los primeros momentos posteriores al sismo, los salvadoreños se percataron de la dimensión del cataclismo hasta que vieron las dramáticas imágenes en televisión. Un terremoto es una noticia que, por sus características, es aprovechada al máximo por los informativos televisivos. Las imágenes del terremoto registradas por una cámara cumplen los requisitos que los expertos señalan como ventajas del video en el plano informativo: credibilidad (creemos lo que vemos), expresividad (la imagen es una expresión en sí misma, no necesita el lenguaje verbal) y el impacto emocional. Esta última característica es vital para la televisión, porque es la que permite "conectar" las emociones de la audiencia con los hechos registrados. Es precisamente el impacto emocional de la imagen lo que aprovechan los noticieros sensacionalistas, cuya frontera con los noticieros "serios" es cada vez más difusa.

Si recordamos el postulado que "noticia es lo que los medios deciden que lo sea", entonces, la noticia estaba en los lugares donde la televisión había concentrado su atención. El resto del país pasó a un segundo plano informativo. Esto podría explicar, en parte, por qué esos lugares no fueron atendidos de inmediato por las brigadas de asistencia del gobierno $y$ otros organismos. Seguramente, repartir viveres en un sitio remoto como Santa Elena (Usulután), no tendría el mismo efeclo propagandístico que hacerlo en Santa Tecla, donde se había concentrado la prensa nacional e intemacional. De este modo, la dimensión de la tragedia fue inferida a partir de los sitios emblemáticos, escogidos por los medios para tal fin. 
Y aunque no cabe duda que en algunos lugares la catástrofe era mayor que en otros, los criterios de selección son cuestionables. Por ejemplo, nadie en su sano juicio pondría en duda la relevancia e impacto que tuvo el terremoto en la colonia La Colina, en Santa Tecla, pero concentrar la atención allí permanentemente, e incluso transmitir en vivo el entiero masivo de cadáveres sin identificar en una fosa común a las diez de la noche es sensacionalismo, en su más pura expresión.

Siguiendo su tradición, los noticieros de televisión, agrupados en la Telecorporación Salvadoreña (TCS), obviaron hasta donde les fue posible cualquier crítica en contra de la política gubemamental de distribución de ayuda. Prefirieron exaltar los "sobrevivientes símbolo" (Sergio Moreno) y "los lugares símbolo" (Comasagua y La Colina). Optaron por explotar lo trágico, sin complicarse en investigaciones serias del por qué tanto desastre en la cordillera del Bálsamo o qué genera y mantiene la vulnerabilidad de la población pobre ante este tipo de tragedias. Aun con problemas logísticos, carencia de recursos y muchas veces, de formación e información sobre estos cataclismos, los periodistas de televisión cumplieron su función pública e informaron a la comunidad de un hecho relevante, que le interesaba y afectaba directamente. Pero luego dejó de ser noticia el terremoto en sí mismo. La cobertura entonces se concentrớ en tres grandes líneas: la descriptiva, la sensacionalista y la crítica.

La línea descriptiva fue una continuidad de la cobertura original, pero en nuevos escenarios, en lugares devastados, que no habian sido tomados en cuenta antes, donde los pobladores formulaban sus peticiones y los periodistas realizaban la cobertura como si el terremoto acabara de ocurrir. La línea sensacionalista fue abundante en información. Con solo anteponer la frase "les advertimos que la siguiente información tiene imágenes fuertes", los periodistas tranquilizaban su conciencia para mostrar cadáveres mutilados, explotar sin misericordia los sentimientos de las víctimas o el drama que les tocaba vivir a los damnificados en los refugios. Fue así, por ejemplo, que una periodista le preguntó a una niña damnificada en Santa Tecla: " ¿tenés frío?", cuando la respuesta era obvia, porque la niña estaba apenas vestida, durmiendo casi a la intemperie $y$, para colmo, el país era afectado por un frente frío.

Otros se dedicaron a simplificar las cosas y a buscar símbolos. Es el caso de la trágica suerte del joven músico Sergio Moreno, explotada desde el momento en que se supo que estaba vivo, entre los escombros de su casa, en la colonia La Colina. Cuando fue rescatado en precarias condiciones vitales, estos periodistas lo identificaron como "el símbolo de la esperanza de una nación". Siguiendo la lógica de este tipo de periodismo, cuando lamentablemente se produjo la muerte del joven, estos noticieros debieron haber informado de "la muerte de la esperanza de esta nación”. Toda la cobertura fue aderezada con música empalagosa y a veces deprimente para crear una almósfera que, lejos de motivar sensibilidad, llegó a la sensiblería o cursilería, lo cual acaba siendo una burla al dolor ajeno, que es explotado con morbo por la prensa amarilla.

La línea crítica se observó cuando algunos medios, desde el primer momento, abrieron sus espacios al servicio social de la población, transmitieron mensajes de personas que buscaban familiares o que deseaban informar que estaban a salvo. Poco a poco, conforme pasaba el tiempo y el gobierno mostraba su ineficacia para administrar y distribuir la ayuda, el descontento entre la población fue aumentando y los mensajes dejaron de ser servicios sociales para convertirse en denuncias de mala, poca o ninguna distribución de ayuda y hasta de casos de corrupción. Los espacios, entonces, se fueron cerrando.

Pero Canal 12 mantuvo la línea crítica concentrada en la figura de su director de noticias, que estuvo al aire maratónicas jornadas de hasta cuatro horas, luego del noticiero estelar. Sin duda, este espacio sirvió como válvula de escape para el descontento de la población y hasta sirvió, aunque tardíamente, para que el gobierno redefiniera su política de distribución de ayuda y la descentralizara, haciéndola más rápida y eficiente. El trabajo de este canal de televisión generó descontento en los sectores conservadores y afines al gobierno. Los medios son muy dados a las crílicas, pero al mismo tiempo son intolerantes cuando son objeto de las mismas. Esto quedó comprobado con el agrio debate, tan apasionado como estéril, entre el director del noticiero del Canal 12, Mauricio Funes y el director de El Diario de Hoy, Enrique Altamirano. Ambos periodistas defendieron desde sus trincheras ideológicas sus conceptos de objetividad y verdad, y se acusaron muluamente de realizar un trabajo antipatriótico, uno por denunciar el presunto manejo oscuro de la ayuda y el otro por no denunciarlo. El debate, que parece inconcluso, no abona en nada a la necesaria despolari- 
zación del país ni a la búsqueda de consensos para impulsar los planes de reconstrucción nacional.

Estuvo mal que ambos ocuparan tanto espacio, esfuerzo y tiempo en desacreditarse mutuamente, a pesar de las razones (y sin razones) de cada uno. No hay espacio aquí para analizar sus argumentos, pero si para que observemos los peligros que todavía enfrenta la prensa cuando asume su rol crítico. Aunque sólo el director de El Diario de Hoy enfrentó directamente a Funes, algunos funcionarios y empresarios también se mostraron en desacuerdo con las críticas hechas por el periodista de Canal 12 (y también con las que vinieron de un buen grupo de corresponsales extranjeros). Hubo intentos de desacreditar los cuestionamientos en contra del gobierno y de CONASOL, difundidos por algunos medios. Parece preocupante, entonces, que intereses políticos (y, sobre todo, económicos) sigan, por un lado, controlando a un buen sector de la prensa $y$, por otro lado, continúen amenazando a la prensa que cuestiona los desaciertos gubernamentales.

\subsubsection{Los diarios: la tragedia que leímos}

Según los expertos, en momentos de crisis, se agravan ciertos vicios en los medios de comunicación, a saber, la trivialización, la fragmentación, la tendencia a destacar lo espectacular y lo dramático, y la falta de auténtica verificación de lo que se divulga. Los vicios antes apuntados aparecieron en el tratamiento periodístico, en casi todos los medios de comunicación, aunque en esto ninguno supera a la televisión, por la explotación excesiva que hizo de las imágenes.

En cuanto a los periódicos, se evalúan aquí los dos matutinos más grandes del país (La Prensa Gráfica y El Diario de Hoy, por ser los de más tiraje, entre otras razones). Dos días después del terremoto, en ambos diarios abundaron las fotografías de gran tamaño que mostraban escenas de mucho dolor, cuerpos mutilados, recién rescatados de los escombros y la tristemente famosa instantánea aérea de la colonia La Colina. Ambos lambién insistieron mucho, especialmente, El Diario de $H o y$, en las historias personales de terror y sufrimiento de los daminificados y los familiares de las víctimas. Así continuaron hasta las primeras semanas de febrero. Lo sustancial quedó perdido muchas veces en lo anecdótico. Faltó profundidad y sobró sensacionalismo, sobre todo en los titulares de los primeros días (" $i$ Corramos, hija, corramos!”, “ ¡Otra vez! Dios mio”, "Sábado negro”, "¿Señor, qué te hemos hecho?”).

La situación misma de emergencia justificó, de alguna manera, la cobertura que dieron los periódicos en los primeros días después del terremoto. Ambos se dedicaron a cuantificar víctimas y daños, a informar sobre las labores de rescate y las evaluaciones de costos, a difundir avisos y consejos de las autoridades a la población, así como a orientar sobre la labor de recolección y distribución de ayuda para los damnificados. Esta labor informativa fue muy útil para muchas personas, en un primer momento, pero fue insuficiente, una vez superada la primera crisis.

La falta de profundidad se observó, sobre todo, en el tratamiento que recibieron dos temas: el derrumbe de La Colina y la polémica por la distribución de la ayuda. En las notas periodísticas, el único esfuerzo serio por explicar qué agravó la tragedia de La Colina se hizo en la revista Enfoques de La Prensa Gráfica, el 21 de enero, una semana después del terremoto. Con una investigación documental, Enfoques señaló pistas que evidenciaron cierta responsabilidad de las constructoras y de las autoridades nacionales, en la devastación de la cordillera del Bálsamo. Enfoques informó sobre algunos esfuerzos que desde finales de los años ochenta, hicieron algunos organismos para proteger la zona de influencia de la cordillera del Bálsamo, en cuyo talud se han construido decenas de proyectos habitacionales como el de La Colina.

La cobertura de los diarios sobre los planes gubemamentales de distribución de ayuda a los damnificados fue poco sistemática. Sí aparecieron en ambos diarios denuncias de algunas comunidades por la larga espera que llevaban por viveres e insumos básicos para protegerse de la intemperie. Las críticas, sin embargo, se presentaron siempre aisladas, sin que se notara ningún esfuerzo de los periodistas por analizar lo que había detrás de la ineficiencia gubernamental ni por analizar qué había fallado exactamente en CONASOL. Antes de que el gobierno decidiera descentralizar sus planes de atención, ninguno de los periódicos habló de "centralización". Después de que el gobierno decidió dar más participación a las alcaldías, sólo La Prensa Gráfica mencionó los desatinos de las autoridades encargadas de recolectar y distribuir la ayuda ${ }^{27}$.

27. Editoriales de La Prensa Gráfica del 18 de enero, p. 47; 22 de enero, p. $34 ; 23$ de enero, p. 23. 
En el tema de La Colina y de la ayuda, la línea editorial de ambos periódicos fue bastante reveladora. El Diario de Hay hizo una clara defensa de la labor de CONASOL y liberó de cualquier responsabilidad a las constructoras por el desastre de La Colina ("la construcción de casas, o la supuesta deforestación, nada tuvieron que ver con la tragedia"23). Asimismo, se esmeró en criticar la labor de denuncia que hacía el periodista Mauricio Funes, en el Canal 12, y los esfuerzos del alcalde Óscar Ortiz, a quien llamaba el líder del "Soviet Supremo de la República Popular de Santa Tecla". En los editoriales de La Prensa Gráfica, por el contrario, aparecieron constantemente palabras que infundían ánimos en la población para salir del sufrimiento; hubo sugerencias para el desarrollo de tareas inmediatas, en la atención de damnificados y reconstrucción; aunque tardíamente, también se hicieron críticas a la centralización que afectaba las labores del gobierno en la distribución de ayuda a los afectados por el terremoto, sin ser muy severos con el gobierno y, al mismo tiempo, con una evidente confianza en el trabajo de CONASOL.

\subsubsection{Lo que quisiéramos ver y leer}

Tras el terremoto, los noticieros de televisión y los periódicos cumplieron un rol satisfactorio como proveedores de información básica para la población. A pesar de esto, ambos se estancaron en una cobertura periodística superficial y sensacionalista, que, lejos de infundir tranquilidad en la población, la exacerbó aún más. Estos errores son especialmente graves en la prensa escrita, ya que cuenta con las características para tratar los temas con más profundidad que los medios electrónicos. Hubo un gran vacío en los grandes periódicos y en la televisoras controladas por el consorcio Eserski: las crílicas en contra del gobierno (por la distribución de la ayuda) y contra las constructoras (por su potencial responsabilidad en el desastre de La Colina).

Momentos después de ocurrido el terremoto, un experimentado periodista de televisión recurrió a la línea abierta en la radio $Y S K L$ para comunicarse con sus compañeros de un noticiero, dado que las líneas habituales estaban interrumpidas. La necesidad es la madre del ingenio. Pero no todos los periodistas tienen tanto ingenio ni entrega. Y dado que el país entero es de alta vulnerabilidad (si no ocurre un terremoto, es un huracán, una inundación o una epidemia), bien harían los periodistas en diseñar planes de contingencia para cubrir cualquier eventualidad. Es parte de su responsabilidad con la sociedad, porque, tal como señala Obach, "a través de la pantalla la mayoría de la sociedad se informa sobre lo que sucede, toma conciencia, se motiva y al final toma una postura". Y lodos esperamos que la información sea de calidad suficiente para tomar una decisión correcta.

\section{La política ante el terremoto}

La polílica es generalmente considerada como la ciencia humana encargada de resolver cierto tipo de conflictos que se dan en la sociedad. Si la sociedad, y con ello la constitución del Estado, es una respuesta a la inseguridad personal, propia del "estado natural", la política sería la instancia —en un sentido más moderno- desde donde se estructura el Estado y el lugar privilegiado para pensar en la satisfacción de las principales demandas de los ciudadanos. En nuestros días, éstos exigen del Estado un poco más que la protección de su persona y de sus bienes; se le exige también, por ejemplo, el establecimiento de políticas públicas, de educación, salud y medio ambiente.

Por lo anterior, se entiende perfectamente que en la génesis del Estado se emplace la política como medio de planificación, gestión y manejo de la sociedad. De esta suerte, resulta también ineludible el carácter político de toda acción estatal sobre la sociedad. En virtud de la vocación del Estado para organizar y gestionar la sociedad, toda acción suya es "política" y se debe analizar desde lo que es $y$, desde allí, cuestionar su eficacia para resolver los problemas sociales a los que dice apuntar. En este sentido, la actual campaña nacional de denuncia en contra de la "politización" de las acciones gubernamentales ${ }^{\text {") }}$ a favor $\longrightarrow$ en detrimento- de los damnificados por el terremoto no tiene razón de ser. Por el contrario, es saludable preguntarse por el tipo de política que han

28. Editorial de El Diario de Hoy del 19 de enero. Ver también editoriales del Ih de enero, p. 49; 18 de enero, p. 55; 23 de enero, p. 23.

29. Ver "Unidad Nacional", El Salvador proceso 938, 7 de febrero de 20()1, pp. 2-3. 
ejercido los responsables del aparato estatal antes de la emergencia y después de ella.

Así, pues, una crítica de la actuación de los sectores implicados en el manejo de la emergencia y la calidad de las políticas públicas es indispensable. Esto último obliga a una reflexión en tomo al tema, tan difundido en la prensa nacional, de una supuesta maldad inherente a la politización de quienes denuncian la parcialidad y los criterios poco claros con los cuales se maneja el país. Hay que sospechar de esta tendencia a anatemizar la polílica. Si bien es cierto que ella no lo consliluye todo en la vida de un país y es necesario que el país aprenda a reflexionar sobre lópicos estriclamente sociales ${ }^{\mathrm{kI}}$, no es menos importante apreciar en su justo valor el posible aporte de la polílica para la solución de los problemas nacionales propios de esta etapa de reconstrucción. En este apartado, se tratará de valorar el desempeño de diferentes instituciones estatales en el enfrentamiento, planificación y mitigación de la emergencia, desde el punto de vista político.

\subsection{Algunos antecedentes}

El Estado salvadoreño, a lo largo de sus 179 años de vida independiente, se ha caracterizado por su incapacidad para dar respuesta a las demandas básicas de seguridad jurídica, económica y social de la mayoría de sus ciudadanos. La ineficiencia y los intereses de determinados grupos de poder han configurado el estilo estatal de enfrentamiento a los problemas de este país. Esta es una de las razones por las que la falta de prevención en caso de desastres, a la que nos hemos referido antes, es un defecto crónico propio de El Salvador. Las instituciones actúan con la más chocante parsimonia ante las demandas y reclamos de los ciudadanos, cuando no es que se dedican, abiertamente, a la defensa de los intereses de los grupos económicamente dominantes.

Como muestra palmaria de lo anterior, está el tema de la responsabilidad estatal en el desprendimiento de tierra en la cordillera del Bálsamo, que soterró más de doscientas viviendas, provocando más de 400 víctimas mortales. Cuando se recuerdan las diferentes protestas de los habilantes de este lugar y las demandas de organizaciones ecológicas, para impedir la construcción en esa parte de la montaña; cuando se recuerda el fallo de la Corte Suprema de Justicia, autorizando a una empresa constructora a seguir con la depredación de esta zona boscosa, la realidad no puede ser más chocante. Lo que sucede, en definitiva, es que el máximo tribunal de justicia del país, al igual que el resto del entramado institucional estatal sigue estando al servicio del "gran capital".

En estas circunstancias, hay que recalcar, en primer lugar, que el evento sísmico, además de pillar desprevenidas a las instituciones nacionales, encargadas de velar por la seguridad ciudadana, también refuerza la imagen de un Estado salvadoreño incapaz, perdido, a la deriva, sin limón. Así, el aporte de las instituciones estatales en el manejo de la crisis ha sido errático, ineficaz y orientado, según los intereses políticos particulares de los grupos que gestionan el aparato estatal. De esta suerte, el estilo con el que las diferentes instiluciones han enfrentado la emergencia desnuda una realidad atravesada por grandes intereses de grupos. El dominio del aparato estatal por estos últimos, la corta visión de los dirigentes, ocupados más en defender su cuota de poder que en llevar soluciones reales a las demandas de la población, un estilo estatal "privatizado" son las notas más sobresalientes del manejo político de la emergencia.

\subsection{El oportunismo de la derecha}

Para los sectores más influyentes de la derecha, la emergencia ha sido vista como un espacio propicio para reafirmar su dominio sobre las diferentes instituciones de la vida nacional. Las primeras intervenciones del Órgano Ejecutivo en este contexto ofrecen un ejemplo bastante ilustrativo del estilo político y los criterios administrativos prevalecientes en este sector. En primer lugar, con sus primeras medidas, el presidente Flores confirmó su incapacidad para enfrentar la realidad del país desde una visión de nación, aglutinadora de las distintas fuerzas sociales y políticas. La conformación de CONASOL es un ejemplo palpable de lo anterior. La lealtad partidaria ha sido la nota dominante, pese a las distintas llamadas de unidad nacional de la presidencia. Se ha usado el tema de la emergencia nacional para entronar a Roberto Murray Meza, el posible candidato de ARENA para suceder a Francisco Flores. Los conlinuos in-

30. Ver "La irrupción de los social", El Salvador Proceso 937, 31 de enero de 2001, pp. 2-3. 
formes de prensa sobre la "entrega" y el "compromiso" de este empresario cervecero revelan bastante bien el propósito. A todas luces, se ha tratado de presentar a este personaje como ejemplo de compromiso con la causa nacional.

La ayuda a las victimas ha sido usada como instrumento de fortalecimiento de la imagen del equipo gubernamental. En efecto, la televisión ha sido prolija en imágenes del Vicepresidente de la República o del Ministro del Interior entregando bolsas de dinero a los diferentes alcaldes del país. No ha importado que la ayuda sea mínima y no responda a las necesidades de los damnificados. La necesidad de una buena imagen ha sido la prioridad de los funcionarios, lo cual, ciertamente, contradice los reiterados llamados a la unidad y a la "no politización" del dolor de los damnificados hechos por el presidente Flores.

En lo que se refiere al tema de la descentralización, en la óptica gubernamental, la misma no va más allá de la entrega de las bolsas de dinero a lós diferentes alcaldes para que ellos a su vez lo distribuyan entre la población afectada. Es una descentralización desde arri-

Las instituciones actúan con la más chocante parsimonia ante las demandas y reclamos de los ciudadanos, cuando no es que se dedican, abiertamente, a la defensa de los intereses de los grupos económicamente dominantes. ba, que no entiende de participación y que, a su vez, menoscaba la autonomía de las municipalidades para decidir en función de las necesidades de sus comunidades. Naturalmente, una descentralización bien entendida restaría protagonismo al ejecutivo, acostumbrado a presentarse como el único foco de referencia - aun en su incompetenciapara hacerle frente a los problemas del país.

Por otro lado, nada es más ilustrativo del afán de protagonismo de la derecha que su airada protesta por la concesión, por parte del gobierno español, de una pequeña ayuda al FMLN, para ciertas alcaldías. La desordenada sensibilidad política del Ministro del Interior pudo más que la delicadeza diplomática y emplazó públicamente al embajador español en el país para que diera explicaciones acerca de la decisión de su gobiemo". No cabe duda de que la derecha, cuando ve amenazados sus intereses, no entien- de de la miseria y del dolor de los "marginales". Cuando se trata de afirmar su férreo control sobre la realidad o cerrarle el espacio a sus adversarios políticos, no entiende ni de recato ni de razones.

En fin, estas $y$ otras medidas hacen pensar seriamente sobre las verdaderas intenciones del ejecutivo ante la calamidad dejada por el terremoto. Ante un oportunismo tan evidente, difícilmente, puede ganar legitimidad el llamado hacia la unidad nacional formulado por el Presidente de la República, al igual que tampoco pueden convencer sus llamados a "nacionalizar la tragedia" y a digerir el dolor ${ }^{32}$.

\subsection{La pasividad de la Asamblea Legislativa}

Aparte de haber sido mencionada en la campaña de prensa encaminada a forzar a la aprobación del presupuesto nacional de emergencia, la Asamblea Legislativa pasó prácticamente desapercibida para los damnificados por la catástrofe. Contribuyó a ello tanto la naturaleza de la tragedia —que, en buena medida, exigía una intervención del ejecutivo- como la misma tozudez de los distintos partidos que la conforman. Una y otra vez se habrían enfrascado en discusiones estériles que en nada habrían contribuido a resolver los problemas de las víctimas del terremoto.

La bancada legislativa arenera se mostró, como siempre, dispuesta a ser caja de resonancia del ejecutivo y de los intereses del sector de los grandes negocios. Desde esta postura, su principal tarea consistió en establecer una alianza con el sector de la prensa, puesto al servicio del gobierno, para desprestigiar a los opositores renuentes a aceptar el presupuesto de crisis presentado por el ejecutivo. Por otro lado, no desaprovecharon la situación para hacer a un lado toda crítica opositora a su manejo del país. Incluso cobró visos de realidad el rumor sobre supuestos actos arbitrarios del presidente de la comisión de hacienda en la Asamblea, Julio Gamero, al introducir cambios en el presupuesto, luego de que el mismo fuera aprobado.

31. Ver El Diario de Hoy, 2 de febrero de 2001, p. 3.

32. Ver "Unidad nacional". El Salvador Proceso. 
Como quiera que sea, las acusaciones y el despliegue de publicidad en torno a la aprobación del presupuesto pusieron de manifiesto la tendencia a excluir a un sector de la oposición de toda discusión del manejo de la crisis. Incluso hubo amenazas de aplicar un régimen de excepción ${ }^{3,}$, previsto por la Constitución en ciertas circunstancias, para así prescindir de la oposición en la Asamblea Legislativa. De nueva cuenta, los sectores de derecha no desaprovecharon la oportunidad para reafirmar su firme convicción de interpretar en cada momento las leyes del país a su antojo y conveniencia.

En la misma línea, se situaron la Democracia Cristiana y el Partido de Conciliación Nacional, cuyos dirigentes no dudaron en dar su apoyo a ARENA. Ni siquiera han manifestado cierta disposición a fiscalizar la actuación del ejecutivo en la atención a los damnificados. Su pretendida defensa de la descentralización de la ayuda y de la participación municipal en la atención a las víctimas se esfumó ante su lealtad a ARENA. Definitivamente, siguen siendo partidos apéndices, dispuestos a "acompañar" - como gustan llamar a la mecánica de levantar la mano"- incondicionalmente cuantas propuestas le vinieran en gana al ejecutivo, inclusive en caso de que estén en clara contradicción con los principios que dicen defender.

\subsection{La confusión de la izquierda}

Las profundas grietas que dejó el terremoto en los suelos del país también alcanzaron las paredes del principal partido de oposición. Al igual que los edificios rajados, en peligro de desplomarse, el FMLN parece entrar en un proceso proclive a desplomarse ante la sacudida del terremoto. En el partido, que suele presentarse como el genuino defensor de los intereses de las mayorías no se ha visto claridad alguna. Una mezcla de ingenuidad politica y ambición electoral lo mantienen perdido en las aguas del protagonismo.

En efecto, el pasado 2 de febrero ${ }^{14}$, la prensa hizo eco del revuelo que causó al interior del FMLN la noticia del viaje a España de uno de sus miembros, Facundo Guardado, ex candidato a la presidencia por el partido de izquierda, invitado a integrar una comitiva gubernamental. Los medios hicieron público el descontento de los responsa- bles del FMLN ante el viaje de Guardado, no sólo por haber ignorado las "órdenes" de su partido, sino también porque con ello estaba contribuyendo a su propio descrédito, dadas las enormes dudas que pesan sobre el partido oficial por su manejo de la ayuda proveniente del exterior. Sin embargo, lo más risible de la situación fue que, dos dias después de haber rechazado a Guardado y de amenazar con posibles sanciones, las autoridades del FMLN anunciaron que habían hecho una lectura diferente de la situación y que, en virtud de ello, no sancionarían al supuesto militante rebelde.

Obviamente, ante tal manifestación de ingenuidad política, la prensa progubernamental no escatimó esfuerzos para denunciar la politización y la falta de sensibilidad del instituto político de izquierda. Es evidente que a estas alturas hay que preguntarse seriamente por la legitimidad de los oficialistas para acusar de politiqueros al FMLN. En buena medida, la mencionada descalificación obedece a su deseo de sacar provecho político de los desatinos obvios del Frente en este tema, aunque ellos mismos han probado desde el inicio de la crisis que estaban dispuestos a capitalizar las acciones en beneficio de ARENA.

Sin embargo, ello no obsta para efectuar un análisis crítico del posicionamiento del FMLN en esta coyuntura. Si bien es cierto que hay que valorar positivamente el hecho de que el FMLN ha sido el único partido político en hacer un esfuerzo público de reflexión y haya presentado a la sociedad una propuesta de reconstrucción, su comportamiento no ha sido del todo ejemplar. En primer lugar, su reacción no ha sido diferente de la de los demás actores políticos. La ingenuidad con la que ha manejado el tema del viaje de uno de sus miembros, acompañando a una comitiva gubernamental, y su incontrolada ansiedad por capitalizar en beneficio propio los errores gubernamentales, no lo sitúa en el mejor lugar ante la opinión pública. Sigue presentando buenos diagnósticos de la realidad del país, pero no logra entender que es parte del sistema y que debe demostrar inteligencia política para poder avanzar en la realización de sus propuestas. La sempiterna denuncia de los vicios de la derecha y de sus políticas neoliberales no lo exime de responsabilidad en la manera cómo se conduce en la política nacional.

33. Ver Diario El Mundo, 17 de enero de 2001, p. 3.

34. Ver La Prensa Gráfica y El Diario de Hoy, 2 de febrero de 2001. 
Por otro lado, especialmente, en lo que se refiere al viaje de Facundo Guardado, los dirigentes del FMLN han manifestado su poca comprensión de la dinámica política del país. Al contrario de lo que pensaban, su protesta desaforada ha dado al tema mayor relevancia de la que merecía. En todo caso, hubieran podido esperar la vuelta del miembro rebelde para amonestario o emplazarlo para que se disculpe por haber ignorado las directrices partidarias, pero cayeron en la tentación de la publicidad, en el mejor estilo de sus rivales de derecha. De esta suerte, ellos mismos han contribuido a la campaña que se ha desatado en su contra y que amenaza con restar legitimidad a las iniciativas efemelenistas.

Es probable que el FMLN esté cegado por sus últimos resultados electorales. Desde que se conocieron dichos resultados, sus líderes han caido en un triunfalismo exagerado, seguros como están de ganar la próxima elección presidencial. Nadie puede ignorar que el objetivo de todo partido político es situarse cómodamente en las preferencias electorales. Sin embargo, el manejo enfermizo de este tema por el FMLN explica en buena medida sus errores en momentos en que el país necesita más de su compromiso con el dolor de los damnificados. Cuidan tanto de lo que consideran sus logros políticos, que ellos mismos terminan minándolos. No quieren entender que harían un mayor bien a la población solidarizándose de verdad con su dolor que buscando a toda costa arrebatar el protagonismo al gobierno.

En suma, frente a la emergencia, los actores políticos nacionales no han estado a la altura de las circunstancias. Cada bando ha intentado capitalizar para sus intereses políticos los "frutos" de la tragedia. El oficialismo, con el apoyo de un sector influyente de la prensa nacional, ha tratado de presentar a la izquierda como la principal responsable del atraso en la atención a los damnificados. La izquierda, por su parte, se ha dedicado a la crítica gubernamental. Los actores políticos no han sabido hacer nada para prevenir los efectos desastrosos del terremoto en la vida del país; tampoco están dando señales de poder enfrentar los daños con la suficiente solvencia. Queda, como única salida, el despertar ciudadano para forzar un cambio en la inercia política predominante.

\section{Conclusiones}

(a) Ante todo, en una sociedad en la que falla el comportamiento organizado de sus miembros, tam- bién falla -y prácticamente de antemano- uno de los requisitos fundamentales de toda respuesta frente a los desastres: la multi-institucionalidad de las acciones emprendidas para restablecer y mejorar la situación de la sociedad. En el afianzamiento de esta deficiencia también interviene la típica actitud de las autoridades gubemamentales de ignorar toda posibilidad de trabajar conjuntamente con otros actores sociales que no gocen de la confianza de los grupos dominantes. En definitiva, mientras se siga depositando ciega confianza en quienes simplemente ocupan un lugar privilegiado entre los asesores cercanos del gobiemo - la composición de CONASOL y la renuencia a reestructurar al COEN son claras muestras de ello-, la posibilidad de abrir espacios para la resolución concertada de las crisis seguirá siendo mínima.

Si no se logra romper este sesgo entre quienes están "a favor" y "en contra" de la iniciativa oficialista, difícilmente se podrá superar la forma en que la iniciativa oficial incluye a la población en los planes de reconstrucción. De momento, el papel de la población afectada se ha reducido a la colaboración en las tareas de limpieza y en la recuperación de materiales reutilizables de entre los escombros de lo que fueron sus hogares o lugares de trabajo. Nada de esto contribuye a generar en esta población afectada un sentido de responsabilidad que les permita capacitarse en la autogestión -al menos a futuro- de los planes de reparación, prevención, mitigación y respuesta a desastres futuros.

Asimismo, si bien es cierto que es responsabilidad de los gobiernos locales colaborar en la elaboración de nuevas estrategias de uso de suelos y de crecimiento urbano - a parte de lo que puedan aportar en la capacidad de organización de la población en situación de riesgo-, también lo es que el gobierno central debe promover de una vez por todas un plan de desarrollo que sea capaz de contrarrestar los focos de vulnerabilidad que posee el país. Hace unos meses, a pocos días de anunciar la Ley de Integración Monetaria, el presidente Flores hizo publica una "Propuesta de acciones territoriales", según la cual se fortaleceria al país, a partir de un esquema que multiplicaría los ejes de desarrollo. Este principio habría sido un buen punto de partida para empezar a actuar a favor de un desarrollo más equitativo y sostenible para la nación.

Por el contrario, la elaboración del plan de reconstrucción nacional — por citar un ejemplo-, que el gobiemo de Flores deberá presentar en pocos me- 
ses, no ha logrado vencer la práctica de las "encerronas" que, dicho sea de paso, ya han demostrado su potencial negativo para los intereses nacionales (recuérdese simplemente la referida Ley de Integración Monetaria). A la larga, se debe trabajar para que, en un futuro cercano, hablar de desarrollo implique hablar de un proceso en el que prive la participación de todos los sectores de la sociedad y en el que se parta del reconocimiento de los errores cometidos para superar los obsoletos marcos de acción que por ahora guían el trabajo de las autoridades.

(b) En segundo lugar, es más que evidente que el aporte de los actores políticos es imprescindible en este contexto para hacer frente con solvencia a los problemas que aquejan actualmente al país. De la colaboración y compromiso de cada uno de los actores depende, en buena medida, la configuración del estilo con el cual se enfrenta el problema y del mismo modo se condicionan las repercusiones sobre la vida nacional. En todo caso, a raíz del terremoto, queda claro que la sociedad salvadoreña debe, principalmente, echar mano de sus propios recursos. De alguna manera, el terremoto puede ayudar a reconstruir los tejidos sociales tan deteriorados en las actuales circunstancias; en la medida en que se enfrente eficazmente esta situación de calamidad, se puede, en el mismo momento, trabajar sobre un tema tan importante como es el refuerzo de los lazos de identidad nacional. El discurso de solidaridad, tan en boga en estos momentos, debe tomarse en serio y llamar a la reflexión a todos los actores sociales. La solidaridad sincera y un moderado optimismo son la mejor terapia colectiva que la sociedad se puede ofrecer a sí misma, en momentos de una crisis tan aguda.

Pero hay que recalcar que esta necesidad de unidad no implica olvidar las responsabilidades ni mucho menos los errores y desatinos cometidos por quienes están obligados a intervenir en la ayuda a las víctimas. Es cierto que es una tarea a la cual la sociedad en su conjunto está llamada a participar. Pero la responsabilidad colectiva no menoscaba el papel de quienes, por obligación constitucional, tienen que responder de manera efectiva a las necesidades de los damnificados. Lo anterior apunta hacia las autoridades que buscan ampararse en la magnitud de la catástrofe para evadir su responsabilidad particular. El país debe pedirles cuenta, tanto por su falta de previsión para la mitigación de desastres como por su ineficiencia en la pronta atención de las victimas.
En este momento, deben cobrar mayor relevancia las voces críticas de la sociedad civil, cuya labor debe consistir en fiscalizar la calidad de la atención a los damnificados por parte de los responsables del Estado. Verbi gratia, debido a la cobertura periodistica, se ha podido llegar a una mejor visión de la amplitud del desastre en momentos en que el Comité de Emergencia Nacional estaba perdido. También fue gracias a la denuncia del excesivo e ineficaz centralismo de los primeros días que el presidente Flores accedió en conferir cierto protagonismo a los municipios en la distribución de la ayuda. Todavía falta mucho por hacer para mejorar el concepto de atención que manejan las autoridades. De un papel subordinado otorgado a los gobiernos locales, se debe llegar al verdadero protagonismo en las decisiones que conciernen a sus respectivas comunidades.

(c) Finalmente, una interrogante que necesariamente hay que hacerse es la siguiente: ¿Reconstrucción o desarrollo pos terremolo? En efecto, si la situación anterior al terremolo no era buena para el país, la situación pos terremoto es mucho peor $y$ obliga al diseño y adopción de programas de desarrollo novedosos, que no solamente persigan la reconstrucción de lo destruido, sino también la superación de las condiciones estructurales que nos hacen más vulnerables a los terremotos, a las tormentas tropicales, a las erupciones volcánicas y a otra infinidad de amenazas socionalurales y antrópicas.

El asunto es cómo manejamos nuestro riesgo para reducir la frecuencia e intensidad de los desastres, y para retirar los obstáculos que se oponen a la consecución del desarrollo sostenible. Lo anterior implica que El Salvador no puede continuar con los mismos patrones de "desarrollo", pues éstos generan las condiciones propicias para la producción de desastres. Es necesario optar por nuevas formas de desarrollo, que consideren de forma transversal el manejo o gestión del riesgo, no sólo porque esto contribuye a prevenir desastres y sus indeseables efectos sobre el desarrollo, sino también porque ello está íntimamente relacionado con el mejoramiento de las condiciones de vida de los sectores sociales más desfavorecidos, empobrecidos y vulnerables del país.

\section{Bibliografía}

Baircs, S. y Lungo, M. De terremotos, derrumbes e inundaciones. San Salvador, LA RED-FUNDE, 1996. 
Benedict L., S. The Salvador Earthquakes of December, 1936. Bulletin of the Seismological Society of America, s.f., Denver.

Bobadilla, J. L.; Cardenas V.; Couttolenc, B. et al. Medición de los costos de la violencia. Resultados de un taller organizado por la Organización Panamericana de la Salud (OPS) y el Banco Interamericano de Desarrollo (BID). Caracas, 11-13 de diciembre, 1995.

Bommer, J., Rola, R. y Méndez, P. Propiedades mecánicas de la tierra blanca y la inestabilidad de taludes. San Salvador, ASIA, 1998.

Bommer, J.; Salazar, W. y Samayoa, R. Riesgo sísmico en la región metropolitana de San Salvador. San Salvador, PRISMA, 1998.

Bommer, J. Terremotos, urbanización y riesgo sísmico en San Salvador. Boletín PRISMA, 18, 1996.

Campos, N., Terremolo y dia de los muertos: elementos para una historia psicosocial del desastre en El Salvador (mimeo). Méxicó, 1987.

Cifuentes, L. I. y White, R. A. Seismic History of the Northwestern Central America Trench and Implications. New York: Columbia University, 1986.

Comisión Económica para América Latina y cl Caribc (CEPAL). División de Planificación de Programas y Opcracioncs. Manual para la estimación de los efectos socioeconómicos de los desassres naturales. Santiago de Chile, ONU, 1991.

Comisión Económica para América Latina y el Caribe (CEPAL). El Salvador: los desastres naturales de 1982 y sus repercusiones sobre el desarrollo económico y social. México, ONU, 1982

Comisión Económica para América Latina y el Caribe (CEPAL). El Salvador: evaluación de los daños ocasionados por el huracán Mitch, 1998. Sus implicaciones para el desarrollo económico y social y el medio ambiente. México, ONU, 1998.

Comisión Económica para América Latina y el Caribe (CEPAL). El terremoto de 1986 en San Salvador: da$\bar{n} o s$, repercusiones y ayuda requerida. Mćxico, ONU, 1986.
Comisión Económica para América Latina y el Curibe (CEPAL). Informe sobre los daños y repercusiones del terremoto de la ciudad de Managua en la economía nicaragüense. México, ONU, 1973.

Jordan, J. y Martínez, M. Seismic History of El Salvador. U.S. Geological Survey, s.f., Denver.

Lavell, A. Desastres naturales y zonas de riesgo en Centroamérica: condicionantes y opciones de prevernión y mitigación. San José: CSUCA, Cuadernos de nvestigación, No. 35, 1988.

Lomnitz, C. y Schulz, R. The San Salvador Earthquake of May 3, 1965. s.1., Scismological Socicty of America, 1966.

Lungo U. M. El terremoto de 1986 en San Salvador y la situación habitacional de los sectores populares. San José, CSUCA, Cuadernos de Investigación, No. $5,1986$.

Martíncz, H. M. Cronología sísmica y eruptiva de la República de El Salvador, a partir de 1520. Ministcrio de Obras Públicas, San Salvador, 1978.

PRISMA. Hacia una estrategia ambiental para la región metropolitana de San Salvador. Bolelín PRISMA 22, 1997.

Romano, L. E. Catálogo de desastres, accidentes y ecología (19/5-1990). San Salvador, CEPRODE, 1997.

Romano, L. E. La protección civil en El Salvador. Propuesta de redefinición. San Salvador, CEPRODE, 1999.

Whitc, R. A. y Harlow, D. H. Destructive Upper-crustal Earthquakes of Central America Since 1900. U.S. Gcological Survey, California, 1990.

White, R. A. Catalog of Historic Seismicity in the Vecinity of the Chixoy-Polochic and Motagua Faults, Guatemala. California: U.S. Geological Survey, s.f.

Wilchez Chaux, Gustavo. Guía de LA RED para la geslión local del riesgo. Auge, caída y levantada de Felipe Pinillo, mecánico y soldador o yo voy a correr el riesgo. Lima, La Red/1T, 1998. 